\title{
San Jose State University
}

From the SelectedWorks of Minghui Diao

April, 2019

\section{Cloud phase and relative humidity distributions over the Southern Ocean in austral summer based on in situ observations and CAM5 simulations}

John J. D’Alessandro, San Jose State University

Minghui Diao, San Jose State University

Chenglai Wu, University of Wyoming

Xiaohong Liu, University of Wyoming

Jorgen B. Jensen, National Center for Atmospheric Research, et al. 
1 Cloud phase and relative humidity distributions over the Southern Ocean in austral summer

2 based on in situ observations and CAM5 simulations

3 John J. D’Alessandro ${ }^{18}$, Minghui Diao ${ }^{1 *}$, Chenglai $\mathrm{Wu}^{2,3}$, Xiaohong Liu ${ }^{2}$, Jorgen B. Jensen ${ }^{4}$,

4 Britton B. Stephens ${ }^{4}$

$5{ }^{1}$ Department of Meteorology and Climate Science, San Jose State University, San Jose, CA, USA,

$6 \quad 95192-0104$

$7 \quad{ }^{2}$ Department of Atmospheric Science, University of Wyoming, Laramie, WY, USA, 82071.

$8{ }^{3}$ International Center for Climate and Environment Sciences, Institute of Atmospheric Physics,

9 Chinese Academy of Sciences, Beijing, China, 1000294

$10 \quad{ }^{4}$ National Center for Atmospheric Research, Boulder, CO, USA, 80301

12 *Corresponding author:

13 Minghui Diao, Assistant Professor

14 Department of Meteorology and Climate Science, San Jose State University

15 One Washington Square, San Jose, CA 95192-0104

16 Minghui.diao@sjsu.edu; Phone: 408-924-7371

$18{ }^{\S}$ Current affiliation of the first author, John D’Alessandro is: Cooperative Institute for Mesoscale

19 Meteorological Studies (CIMMS) and School of Meteorology, University of Oklahoma, Norman, 20 OK, USA, 73019. 


\section{Abstract}

22 Cloud phase and relative humidity $(\mathrm{RH})$ distributions at $-67^{\circ}-0^{\circ} \mathrm{C}$ over the Southern Ocean during 23 austral summer are compared between in situ airborne observations and global climate simulations.

24 A scale-aware comparison is conducted using horizontally averaged observations from $0.1-50 \mathrm{~km}$.

25 Cloud phase frequencies, RH distributions and liquid mass fraction are found less affected by 26 horizontal resolutions than liquid and ice water content (LWC, IWC), liquid and ice number 27 concentrations $\left(\mathrm{Nc}_{\text {liq }}, \mathrm{Nc}_{\text {ice }}\right.$ ), and ice supersaturation (ISS) frequency. At $-10^{\circ}-0^{\circ} \mathrm{C}$, observations 28 show $27 \%-34 \%$ and $17 \%-37 \%$ of liquid and mixed phases, while simulations show $60 \%-70 \%$ 29 and $3 \%-4 \%$, respectively. Simulations overestimate (underestimate) LWC and $\mathrm{Nc}_{\text {liq }}$ in liquid 30 (mixed) phase, overestimate $\mathrm{Nc}_{\text {ice }}$ in mixed phase, underestimate IWC in ice and mixed phases, 31 and underestimate (overestimate) liquid mass fraction below (above) $-5^{\circ} \mathrm{C}$, indicating that 32 observational constraints are needed for different cloud phases. RH frequently occurs at liquid 33 saturation in liquid and mixed phases for all datasets, yet the observed RH in ice phase can deviate 34 from liquid saturation by up to $20 \%-40 \%$ at $-20^{\circ}-0^{\circ} \mathrm{C}$, indicating that the model assumption of 35 liquid saturation for coexisting ice and liquid is inaccurate for low liquid mass fractions $(<0.1)$. 36 Simulations lack RH variability for partial cloud fractions (0.1-0.9) and underestimate 37 (overestimate) ISS frequency for cloud fraction $<0.1(\geq 0.6)$, implying that improving RH subgrid38 scale parameterizations may be a viable path to account for small-scale processes that affect RH 39 and cloud phase heterogeneities. Two sets of simulations (i.e., nudged, collocated and free40 running) show very similar results (except for ISS frequency) regardless of sample sizes, 41 corroborating the statistical robustness of the model-observation comparisons. 


\section{Introduction}

Clouds over the Southern Ocean are an essential component controlling the energy budget over the region and have an annual mean spatial fraction around 80\%-90\% (e.g, Kay et al. 2012; McCoy et al. 2014a; Matus and L'Ecuyer 2017). Climate models show large deficiencies in simulating radiative fluxes in the Southern Ocean region $\left(\sim 50^{\circ}-80^{\circ} \mathrm{S}\right)$, and often underestimate

47 reflected shortwave radiation on the order of $10 \mathrm{~W} \mathrm{~m}^{-2}$ (e.g., Bodas-Salcedo et al. 2014; Li et al. 2013; Kay et al. 2012). This is in part due to the fact that climate models (e.g., Trenberth and Fasullo 2010; Kay et al. 2016a; Bodas-Salcedo et al. 2016; Kay et al. 2016b; Cesana and Chepfer 2013; Wang et al. 2018) as well as higher-resolution regional models (e.g., Huang et al. 2014, 2015) generally show lower cloud fraction and less supercooled liquid water (SLW, i.e., liquid water existing at temperatures below $0^{\circ} \mathrm{C}$ ) than the observations in the mid- and high southern latitudes. The amount of SLW plays a critical role in determining cloud radiative forcing (e.g., Ceppi et al. 2014; Lawson and Gettelman 2014; Shupe and Intrieri 2004), cloud feedbacks (e.g., mixing, which can both substantially alter the radiation budget (Sun and Shine 1994). particles and SLW droplets coexist, ice particles grow at the expense of neighboring supercooled 63 liquid droplets, when the equilibrium water vapor partial pressure (e) is less than the saturation 64 vapor pressure with respect to liquid (esliq) and greater than the saturation vapor pressure with 
respect to ice (esice) (Wegener 1911; Bergeron 1928, 1935, Findeisen 1938, 1940). Ambient

66 relative humidity $(\mathrm{RH})$ has large impacts on cloud phase transition and evolution, therefore

67 quantifying RH conditions becomes a key step for understanding the existence of SLW. Generally

68 speaking, when vapor diffusion effectively equilibrates the vapor pressure between liquid and ice

69 phases, the local $\mathrm{RH}$ reaches a steady state around liquid saturation. This feature is frequently

70 shown by in situ observations on the horizontal scales of $\sim 100 \mathrm{~m}$ (Korolev and Isaac 2006) and

71 cloud-resolving model simulations (Fan et al. 2011). Such assumption of liquid saturation for in-

72 cloud RH when ice and liquid coexist is also used in the parameterization of mixed phase stratiform

73 clouds (Rotstayn et al. 2000), which has been adopted in several global climate models (GCMs),

74 including the Community Atmosphere Model version 5 (CAM5) (Gettelman et al. 2010;

75 Gettelman and Morrison 2015; Morrison and Gettelman 2008), the European Centre for Medium-

76 Range Weather Forecasts (ECMWF) model (Forbes and Ahlgrimm 2014), and the atmospheric

77 component of the Geophysical Fluid Dynamics Laboratory (GFDL) coupled GCMs - CM2

78 (Anderson et al. 2004) and CM3 (Donner et al. 2011). Previously, Fu et al. (2004) compared the

79 in-cloud water vapor parameterizations with 1-s in-situ observations in the Arctic. However, the

80 RH conditions as well as other cloud microphysical properties in MPCs have not been examined

81 and compared for various scales of observations from sub-kilometer to tens and hundreds of

82 kilometers.

Validating simulated cloud properties and processes within climate models is crucial as

84 many uncertainties still remain in predicting cloud feedbacks on climatic time scales (Gettelman

85 and Sherwood 2016). Adjusting the parameterized phase partitioning of cloud liquid and ice can

86 either increase or decrease the climate sensitivity parameter when introducing surface temperature

87 perturbations ( $\mathrm{Li}$ and Le Treut 1992). Tan et al. (2016) constrained the mean state of phase 
partitioning in the Community Earth System Model (CESM, of which CAM is a component) simulations using satellite observations and found an increase in equilibrium climate sensitivity by up to $1.3 \mathrm{~K}$ with a doubling of $\mathrm{CO}_{2}$, resulting from a weakened negative cloud phase feedback. Frey and Kay (2017) also found a $1.5 \mathrm{~K}$ increase in equilibrium climate sensitivity, partly due to reduced negative cloud phase feedback over the Southern Ocean when decreasing the prescribed cloud ice fraction in the total water detrained from shallow convection (Kay et al. 2016a). McCoy et al. (2014b) showed increasing upwelling shortwave radiation due to liquid replacing ice and increasing optical depths as a result of $1 \mathrm{~K}$ tropospheric warming. Climate models were also reported to have difficulties capturing low-level clouds in the cold sector of midlatitude cyclones, potentially due to the prevalence of boundary layer clouds being commonly associated with largescale subsidence in these regions (Govekar et al. 2014; Bodas-Salcedo et al. 2014), which highlights the importance of local processes relative to large scale processes, e.g., cyclonic activity.

Previously, due to the scarcity of in situ observations over the Southern Ocean, only a few studies analyzed in situ observations (e.g., Huang et al. 2015; Ahn et al. 2017; Chubb et al. 2013; Huang et al. 2017; Ovarlez et al. 2002; Morrison et al. 2010; Jensen et al. 2000) and none of them was directly compared with GCM simulations. In fact, most studies relied on spaceborne observations to analyze cloud microphysical properties (e.g., Bodas-Salcedo et al. 2012, 2014, 2016; McCoy et al. 2016; Cesana et al. 2015; Hu et al. 2010; Morrison et al. 2011a; Huang et al. 2012a,b; Matus and L'Ecuyer 2017) and RH distributions (Lamquin et al. 2012; Gettelman et al. 2006; Kahn et al. 2009; Spichtinger et al. 2003) over this remote region. Although the satellite data provide useful information for climatological purposes, their phase determination often includes a large amount of undefined-phase clouds, and various active and passive detection approaches have large differences in their sampling, accuracy, sensitivity, and assumptions (Nasiri and Kahn 2008; 
111 Kahn et al. 2011; Cho et al. 2009; Hu et al. 2009; Chylek et al. 2006; Naud et al. 2006; Riedi et al. 112 2010). For example, the Cloud-Aerosol Lidar and Infrared Pathfinder Satellite Observation 113 (CALIPSO) cloud phase identification is mostly affected by the cloud top (Cesana et al. 2016); the 114 Moderate Resolution Imaging Spectroradiometer (MODIS) cloud-top phase product has limited 115 accuracy from $-25^{\circ}$ to $-5^{\circ} \mathrm{C}$ (Morrison et al. 2011a); the Polarization and Directionality of Earth 116 Reflectances (POLDER) spaceborne instrument uses visible and near-infrared channels, and has 117 difficulties detecting very thin clouds and cloud edges as well as defining phases for multi-layer 118 clouds (Goloub et al. 2000; Riedi et al. 2001). In addition, it is difficult for satellites to retrieve 119 high-resolution RH distributions relevant to cloud-scale microphysical processes. For example, 120 the NASA Atmospheric Infrared Sounder (AIRS)/Advanced Microwave Sounding Unit (AMSU)

121 temperature and water vapor retrievals have vertical and horizontal resolutions of 1-3 $\mathrm{km}$ and $12245 \times 45 \mathrm{~km}$, respectively, and have differences of $\sim 1-2.5 \mathrm{~K}$ in temperature and $\sim 20 \%-60 \%$ in water 123 vapor compared with in situ observations (Diao et al. 2013). In contrast, 1-Hz in situ measurements 124 obtained from research aircraft have horizontal resolutions ranging from 100-250 m. Previously, 125 in situ measurements of $\mathrm{RH}$ and cirrus cloud microphysical properties were analyzed for 126 temperatures $<-40^{\circ} \mathrm{C}$ over Punta Arenas, Chile (Ovarlez et al. 2002; Gayet et al. 2006), yet a 127 comprehensive analysis for $-40^{\circ}-0^{\circ} \mathrm{C}$ is still missing. The purpose of this study is to examine the distributions of cloud phases and RH during austral summer over the Southern Ocean based on in situ observations, and compare with CAM5 130 simulations. Observations from the National Science Foundation (NSF) $\mathrm{O}_{2} / \mathrm{N}_{2}$ Ratio and $\mathrm{CO}_{2}$ 131 Airborne Southern Ocean Study (ORCAS) (Stephens et al. 2018) took place during the austral 132 summer, a time at which a deep, circumpolar storm track often occurs (Hoskins and Hodges 2005). 133 Effects of horizontal spatial resolution on the analyses are examined by spatially averaging 
134 observations from sub-kilometer to tens of kilometers. A series of model-observation comparisons

135 have been conducted, including cloud phase distributions at various temperatures, cloud 136 microphysical properties (i.e., liquid and ice water content (LWC and IWC), liquid and ice number 137 concentration $\left(\mathrm{Nc}_{\text {liq }}\right.$ and $\left.\mathrm{Nc}_{\text {ice }}\right)$ ) for three cloud phases, and $\mathrm{RH}$ frequency distributions. The 138 prerequisite condition of ice particle formation - ice supersaturation (ISS=RHi-100\%) - has also 139 been compared between observations and simulations from $-67^{\circ}$ to $0^{\circ} \mathrm{C}$. These comparisons will 140 help to improve the representations of cloud thermodynamic phases and to reduce bias of the 141 amount of SLW over the Southern Ocean in GCM simulations.

\section{2. Dataset and experimental set-up}

\subsection{In situ observations}

This study uses 1-Hz airborne measurements from the NSF Gulfstream-V (GV) research 145 aircraft during the ORCAS campaign (Stephens 2017). ORCAS took place from January 15 146 February 28,2016 , sampling over the Southern Ocean from $30^{\circ} \mathrm{S}$ to $75^{\circ} \mathrm{S}$ and $50^{\circ} \mathrm{W}$ to $92^{\circ} \mathrm{W}$. The 147 ORCAS campaign conducted 19 research flights, and 18 of them reported final data with 95 148 hours of flight time in total. Details on flight objectives and analyses can be found in Stephens et 149 al. (2018). Observations in this study are restricted to temperatures $<0^{\circ} \mathrm{C}$ to exclude warm cloud 150 measurements (i.e., clouds with no ice or SLW). The total flight time at $-40^{\circ}-0^{\circ} \mathrm{C}$ is 40 hours. In151 cloud sampling time for $-10^{\circ}-0^{\circ} \mathrm{C},-20^{\circ}--10^{\circ} \mathrm{C},-30^{\circ}--20^{\circ} \mathrm{C},-40^{\circ}--30^{\circ} \mathrm{C}$ and $<-40^{\circ} \mathrm{C}$ is $3.2,1.2$, $1521.2,0.73$, and 1.3 hours, respectively. The flights in the ORCAS campaign often sampled cyclones 153 and frontal systems associated with strong westerly flow around the Drake Passage and nearby 154 regions. These synoptic scale conditions coupled with cool ocean surface led to frequent cloud 
stratocumulus. Multi-layer stratus and single-layer stratocumulus have been frequently observed in several flights.

Temperature was measured using a Rosemount temperature probe, having an accuracy and precision of $\pm 0.3 \mathrm{~K}$ and $0.01 \mathrm{~K}$, respectively. Water vapor measurements are taken from the 25 Hz Vertical Cavity Surface Emitting Laser (VCSEL) hygrometer (Zondlo et al. 2010), which has an accuracy and precision of $\sim 6 \%$ and $\leq 1 \%$, respectively. Final data of water vapor mixing ratio and temperature were reported at $1 \mathrm{~Hz}$. Two sets of RH data are calculated, i.e., RH with respect to liquid (RHliq) and ice (RHi), based on Murphy and Koop (2005) that derived esliq and esice from a synthesis of laboratory results. For temperatures relevant in this study at $-69^{\circ} \mathrm{C}$ to $0^{\circ} \mathrm{C}$, the uncertainties in RHi range from $7.5 \%-6.5 \%$, and the uncertainties in RHliq range from $10.4 \%-$ $6.4 \%$, respectively. Due to combined uncertainties from water vapor and temperature measurements, the observed RHliq greater than liquid saturation is set to be equal to $100.01 \%$ (processed for $7745 \mathrm{~s}$ of observations). Such restriction does not alter the number of occurrences for liquid or ice supersaturation.

Cloud particle measurements were made by the Fast 2-Dimensional Optical Array Cloud probe (Fast-2DC) and the Cloud Droplet Probe (CDP). The CDP measures particles ranging from 2-50 $\mu \mathrm{m}$. The Fast-2DC detects particles from 62.5-1600 $\mu \mathrm{m}$ in diameter (excluding the first two bins), and larger particles can be mathematically reconstructed up to $3200 \mu \mathrm{m}$. The mass concentrations for Fast-2DC are calculated based on Brown and Francis (1995). We define incloud conditions as having either of these two conditions: (1) CDP measurements report both number concentration $>0.03 \mathrm{~cm}^{-3}$ and derived mass concentration $>3.98 \times 10^{-4} \mathrm{~g} \mathrm{~m}^{-3}$; (2) Fast-2DC measurements detect at least one particle in a second, and its minimum derived mass concentration was $4.68 \times 10^{-5} \mathrm{~g} \mathrm{~m}^{-3}$ in the ORCAS campaign. The rest of the measurements are defined as clear- 
179 sky conditions. The CDP threshold was chosen in order to minimize the impacts of giant aerosols, which were determined by the relationships between number and mass concentrations (Figure 1).

\subsection{Global climate model simulations}

The model used here is CAM5, which is the atmospheric component of NCAR CESM. A detailed description of CAM5 can be found in Neale et al. (2012). Of particular relevance to this study are the representation of cloud macrophysics (Park et al. 2014), cloud microphysics (Morrison and Gettelman 2008) and shallow convection (Park and Bretherton 2009). Cloud microphysics is coupled with a modal aerosol module (MAM) (Liu et al. 2012) for aerosol-cloud interactions. The version of MAM with three modes (MAM3) is adopted here. Cloud droplets can form via the activation of aerosols (Abdul-Razzak and Ghan 2000). Ice crystals can form via the homogeneous nucleation of sulfate aerosol and/or heterogeneous nucleation of dust aerosol (Liu and Penner 2005; Liu et al. 2007). Hallet-Mossop ice multiplication (secondary ice production) due to accretion of drops by snow is included following Cotton et al. (1986).

Results from in situ observations are compared with two types of CAM5 simulations: the nudged simulation and the free-running simulation. Both simulations were run with a finite volume dynamical core (Lin 2004), a horizontal spatial resolution of $0.47^{\circ} \times 0.63^{\circ}$, a pressure top of $30 \mathrm{hPa}$ and a timestep of $1800 \mathrm{~s}$. The number of vertical levels for nudged and free-running simulations is 56 and 30, respectively. The nudged CAM5 simulation (hereafter named as "CAM-collocated") was forced to represent meteorological conditions (3-D temperature and wind speed) according to the NASA Goddard Earth Observing System Model version 5 (GEOS-5) data (Lamarque et al. 2012), and the output were saved along the aircraft flight track. The detailed nudging method is described in $\mathrm{Wu}$ et al. (2017) and Zhang et al. (2014). The free-running CAM5 simulation 201 (hereafter named as "CAM-domain") was run with prescribed climatological sea surface 
temperature and sea ice extent. The simulation covered the duration of the ORCAS campaign with

203 a 1-year spin-up time and 6-hourly output (00, 06, 12 and 18 UTC). Outputs with the nearest time

204 to the mid-point time stamp of each research flight are selected, which forms a composite CAM-

205 domain data with 18 model outputs, restricted to the horizontal regions $\left(50^{\circ} \mathrm{W}\right.$ to $92^{\circ} \mathrm{W}$ and $30^{\circ} \mathrm{S}$

206

to $75^{\circ} \mathrm{S}$ ) and altitudes (pressure $>176.38 \mathrm{hPa}$ ) comparable to the flight domain.

For analyses of cloud microphysical properties, the model output variables used are "LWC", "IWC", "NUMLIQ" ( $\left.\mathrm{Nc}_{\text {liq }}\right)$ and "NUMICE" $\left(\mathrm{Nc}_{\mathrm{ice}}\right)$, all of which are grid box average quantities. When defining in-cloud conditions, either the value of LWC or IWC being greater than with IWC and LWC in clear-sky conditions set to be zero. Such definition is consistent with the minimum value of mass concentration detected by in situ observations. The calculation of RHi and RHliq is based on Goff and Gratch (1946) in the CAM5 simulations. Since the observations 214 calculate saturation vapor pressures based on equations from Murphy and Koop (2005), both RHi 215 and RHliq values have differences within $\pm 0.3 \%$ compared with those calculated from Goff and 216 Gratch (1946).

\subsection{Spatial averaging of observations}

One of the main challenges for comparing in situ observations and global climate model

219 simulations is their differences in spatial resolution. To address this inherent problem, 1-Hz 220 airborne observations were averaged over various time intervals, i.e., $10 \mathrm{~s}, 25 \mathrm{~s}, 50 \mathrm{~s}, 100 \mathrm{~s}$ and

$221200 \mathrm{~s}$ (named as Obs-Xs). The GV aircraft true air speed ranges from $\sim 100$ to $250 \mathrm{~m} \mathrm{~s}^{-1}$ from near 222 surface to the upper troposphere and lower stratosphere (UT/LS), respectively. Thus, spatially 223 averaged observations at 10-200 s intervals have horizontal resolutions of $\sim 1-20 \mathrm{~km}$ near surface 224 and $\sim 2.5-50 \mathrm{~km}$ at UT/LS (Table S1). Such averaging mostly stands for horizontal averaging since 
225 aircraft true air speed is one to two orders of magnitude higher in the horizontal direction than in

226 the vertical direction. No spatial averaging was applied to CAM-collocated or CAM-domain data,

227 and they have horizontal resolutions of $14-70 \mathrm{~km}$ from higher to lower latitudes $\left(75^{\circ} \mathrm{S}-30^{\circ} \mathrm{S}\right)$,

228 comparable to the Obs-100s and Obs-200s data at 10-50 km resolutions, respectively.

Cloud fraction for observations is calculated as the number of $1-\mathrm{Hz}$ in-cloud data divided

230 by the total number of $1-\mathrm{Hz}$ data during the averaging time interval ( $\Delta$ time). Temperature, RHi,

231 RHliq, $\mathrm{LWC}, \mathrm{IWC}, \mathrm{Nc}_{\text {liq }}$ and $\mathrm{Nc}_{\text {ice }}$ are averaged over the entire time interval, which correspond

232 well with the grid-average variables from CAM5. A "moving average" method is applied for each

233 1-Hz sample by averaging between $\pm \mathrm{N}$ seconds or between $-\mathrm{N}$ and $\mathrm{N}+1$ seconds, where $\mathrm{N}$ equals

$234(\Delta$ time-1)/2 or $\Delta$ time/2 for odd or even $\Delta$ time values, respectively. If more than $10 \%$ of a time 235 interval reports missing data, that sample would be discarded.

\section{3. Results}

\subsection{Definition of three cloud phases}

Cloud phase is defined by the mass fraction of LWC with respect to cloud water content

239 (CWC, i.e., $\mathrm{CWC}=\mathrm{IWC}+\mathrm{LWC}$ ), similar to the definition used in Korolev et al. (2003). A given 240 cloud sample is considered ice phase at LWC/CWC $\leq 0.1$, mixed phase at $0.1<\mathrm{LWC} / \mathrm{CWC}<0.9$ and

241 liquid phase at $\mathrm{LWC} / \mathrm{CWC} \geq 0.9$. This definition is applied to both observations and simulations.

Figure 1 a shows a diagram of the cloud phase identification method. All cloud

243 hydrometeors below $-40^{\circ} \mathrm{C}$ are considered ice. LWC and IWC are derived from two cloud probes

244 by combining their ice and liquid measurements, respectively. After removing large aerosols

245 (Section I in Figure 1 a), samples detected by CDP are considered liquid if number concentration

$246\left(\mathrm{Nc}_{\mathrm{CDP}}\right)>10^{-0.5} \mathrm{~cm}^{-3}$ (i.e., $0.316 \mathrm{~cm}^{-3}$ ), otherwise they are considered ice. At $-30^{\circ}-0^{\circ} \mathrm{C}, 2 \mathrm{DC}$ 
247 measurements are considered ice when the maximum diameter $\left(D_{m_{2} \_2 D C}\right)>312.5 \mu \mathrm{m}$ within a 1-

$248 \mathrm{~Hz}$ measurement by 64 diodes. They are considered liquid for $\mathrm{D}_{\max \_2 \mathrm{DC}}<112.5 \mu \mathrm{m}$. For $112.5 \mu \mathrm{m}$

$249 \leq \mathrm{D}_{\text {max } 22 \mathrm{DC}} \leq 312.5 \mu \mathrm{m}$, the 2DC sample is considered liquid when the 1-Hz standard deviation of 250 particle diameters $\left(\sigma_{\mathrm{D} \_2 \mathrm{DC}}\right) \leq 50 \mu \mathrm{m}$, while the rest of the samples at this $\mathrm{D}_{\text {max } \_2 \mathrm{DC}}$ range are 251 considered ice. At $-40^{\circ}$ to $-30^{\circ} \mathrm{C}$, a $2 \mathrm{DC}$ sample can only be identified as liquid if the concurrent 252 CDP measurement is liquid, as well as the aforementioned criteria for liquid phase are satisfied. 253 Otherwise, that 2DC sample is identified as ice. These key thresholds are illustrated in the 254 relationships of number versus mass concentrations (Figure $1 \mathrm{~b}$ and $\mathrm{c}$ ). The fundamental concept 255 of using $\mathrm{D}_{\max \_2 \mathrm{DC}}$ and $\sigma_{\mathrm{D} \_2 \mathrm{DC}}$ is similar to the method in McFarquhar et al. (2007), but the 256 thresholds have been further adjusted for the instrumentation on GV aircraft, and verified by 257 examining the 2DC imagery and comparing with measurements from the King and RICE probes. 258 In addition, a slightly different cloud phase identification method without the temperature 259 threshold of $-30^{\circ} \mathrm{C}$ for the $2 \mathrm{DC}$ probe was used to analyze an earlier version (April 2018) of the 260 ORCAS data (D’Alessandro 2018). Sensitivity tests show differences mostly within $10 \%$ for cloud 261 phase occurrence frequencies, when examining various thresholds of $\mathrm{D}_{\max \_2 \mathrm{DC}}, \sigma_{\mathrm{D} \_2 \mathrm{DC}}, \mathrm{Nc}_{\mathrm{CDP}}$, etc. 262 (supplementary Figure S1)

Time series in Research Flight (RF) 17 and 03 illustrate two typical model-observation 264 discrepancies, that is, simulations misidentifying liquid and mixed phases as ice phase (Figure 2) 265 and misidentifying ice phase as liquid and mixed phases (Figure 3). Cloud phases are highlighted 266 by colored markers below the abscissa ( $\mathrm{d}$ and e). Exemplary Fast-2DC images show good 267 agreement with the cloud phases being identified (g). In addition, when SLW droplets are 268 identified, the King probe often reports $\mathrm{LWC}>0.1 \mathrm{~g} \mathrm{~m}^{-3}$ (d). The King probe infers LWC by the 269 power required to evaporate cloud droplets after their impact with the hotwire (King et al. 1978), 
270 which may involve biases in LWC when sampling droplets larger than $100 \mu \mathrm{m}$ (Biter et al. 1987)

271 and/or ice particles (Baumgardner et al. 2017). An additional verification of the cloud phase

272 identification method is conducted by comparing with the Rosemount Icing detector (RICE)

273 (Figure S2).

$\mathrm{RH}$ values are less variable in averaged observation data $(\mathrm{a}-\mathrm{c})$, and compare well with 275 simulations for liquid and mixed phases. However, at RF03 UTC 17:45:00-17:51:00, CAM-

276 collocated data show RHi at or above ice saturation (Figure 3 c) with coexisting liquid and ice (e),

277 as opposed to the observations that are almost exclusively ice phase at ice subsaturation, potentially

278 from sedimentation $(b-d)$. The underestimated occurrences of ice subsaturation are found to be a

279 common problem in CAM5 simulations, and will be discussed further in Section 3.4. The CDP,

280 Fast-2DC probes and the VCSEL hygrometer all provide open-path measurements, and their data

281 recording synchronization is within milliseconds. For occasions where liquid cloud edge does not 282 match with liquid saturation, it could be due to the combined uncertainties in RHliq (i.e., $6.4 \%-$ 283 10.4\%) and/or distance between the cloud probes and the VCSEL hydrometer.

Four typical cloud phase segments are seen: (i) a homogeneous, liquid dominant condition (e.g., RF03 UTC 17:38:40-17:41:20), (ii) a homogeneous, ice dominant condition potentially from 286 sedimentation (e.g., RF03 UTC 17:44:30-17:52:00), (iii) a relatively well-mixed segment of 287 mixed phase (e.g., RF17 UTC 19:42:35-19:43:20), and (iv) a spatially heterogeneous mixed phase 288 with a mixture of ice and liquid (e.g., RF17 UTC 19:39:15-19:41:05 and RF03 UTC 17:52:00289 17:58:40). Separate pockets of pure ice, pure water and a mixture of both were seen on the order 290 of hundreds of meters based on $1-\mathrm{Hz}$ data, similar to those pockets reported in Korolev et al. 291 (2003), also known as the "conditionally" mixed phase clouds (Korolev et al. 2017). Large spatial 292 heterogeneities in mixed phase are consistent with those reported by several previous studies, such 
293 as the global survey of cloud thermodynamic phase on the sub-km scales based on Hyperion

294 imaging spectrometer onboard NASA's Earth Observer 1 (EO-1) spacecraft (Thompson et al.

295 2018), 20-m horizontal resolution satellite data of Arctic clouds (Chylek and Borel 2004), as well

296 as 100-m horizontal resolution in situ and ground-based observations of midlatitude MPCs (Field

297 et al. 2004).

\subsection{Cloud phase frequencies and characteristics}

Cloud phase occurrence frequencies are examined for all in-cloud conditions (Figure 4), as well as $\mathrm{CWC} \geq 0.01 \mathrm{~g} \mathrm{~m}^{-3}$ and cloud fraction $\geq 0.6$ (Table 1 ). More sensitivity tests using various incloud thresholds are shown in Figures S3-S5. Spatially averaging 1-Hz observations into $200 \mathrm{~s}$ intervals has approximately doubled the occurrence frequency of mixed phase samples from $17 \%$ to $37 \%$ at $-10^{\circ}-0^{\circ} \mathrm{C}$ and lowered the occurrence frequencies of liquid and ice phase samples when restricting CWC $\geq 0.01 \mathrm{~g} \mathrm{~m}^{-3}$ (Table 1). Coarser resolution observations show more "conditionally" mixed phase samples than higher resolution data due to spatial averaging of individual cloud phase pockets, as discussed in Korolev et al. (2017). In addition, the spatial averaging leads to fewer liquid phase samples that satisfy the condition of cloud fraction $\geq 0.6$ (i.e., $41 \%$ for Obs- 1 s and $5 \%$ for Obs-200s). This is also partly due to vertical profiling of the research aircraft at low altitudes, which leads to relatively short residence time in boundary layer clouds. Total number of seconds and lengths of samples based on mean true air speed at various temperature ranges is given in

311 Table S2.

Compared with observations, both simulations have significantly lower frequencies of 313 mixed phase samples, regardless of the restrictions on in-cloud conditions (Figures 4, S3-S5 and 314 Table 1). For $\mathrm{CWC} \geq 0.01 \mathrm{~g} \mathrm{~m}^{-3}$, from $-20^{\circ}-0^{\circ} \mathrm{C}$, the Obs-200s data show $17 \%-37 \%$ of mixed 315 phase, while both CAM-collocated and CAM-domain data show only about 1\%-4\%. Interestingly, 
both simulations show more liquid phase samples $(60 \%-70 \%)$ compared with the Obs-200s data (27\%) from $-10^{\circ}-0^{\circ} \mathrm{C}$. From $-20^{\circ}--10^{\circ} \mathrm{C}$, the CAM-collocated data also contain $53 \%$ of liquid phase, which is three times of that in the Obs-200s (16\%), and underestimate frequencies of ice and mixed phase samples. Previously, CAM5 simulations have been reported to underestimate SLW content and overproduce ice at temperatures relevant for mixed phase conditions compared with satellite observations (e.g., Komurcu et al. 2014; Cesana et al. 2015; Kay et al. 2016b; Wang et al. 2018). Comparing these previous findings with our results on phase frequencies indicates that satellite observations may be biased to detect a layer of SLW at the top of cold clouds (e.g., Rauber and Tokay 1991) and underestimate ice phase occurrence frequency below cloud top, and/or the underestimation of SLW content in simulations is more likely attributed to underestimating mixed phase frequencies than overestimating liquid phase frequencies. More assessment is needed for the vertical distribution and lifetime of SLW in various cloud phases.

For the examination of liquid and ice mass partitioning, normalized frequencies of LWC/CWC ratios are binned by $10^{\circ} \mathrm{C}$ (Figure 5) and $5^{\circ} \mathrm{C}$ (Figure S6) intervals from $-40^{\circ}-0^{\circ} \mathrm{C}$, separated into two categories, $\mathrm{CWC} \geq 0.01 \mathrm{~g} \mathrm{~m}^{-3}$ and cloud fraction $\geq 0.6$. All of the observations and simulations show decreasing frequencies of liquid phase (i.e., $\mathrm{LWC} / \mathrm{CWC} \geq 0.9$ ) and increasing frequencies of ice phase (i.e., LWC/CWC $\leq 0.1$ ) with decreasing temperature, consistent with more favorable thermodynamic conditions for ice phase at lower temperatures. The threshold of $\mathrm{CWC} \geq 0.01 \mathrm{~g} \mathrm{~m}^{-3}$ is the same as that used in Korolev et al. (2003). Under this condition, the 1-Hz observations reveal similar distributions of cloud phase occurrence frequencies to those shown in Korolev et al. (2017), which recalculated Nevzorov probe measurements initially reported by Korolev et al. (2003) inside clouds in frontal systems. Specifically, 1-Hz observations in the ORCAS campaign show similar frequencies of liquid (34\%), mixed (17\%), and ice phases (49\%) 
339 from $-10^{\circ}-0^{\circ} \mathrm{C}$, comparable to $\sim 37 \%, 20 \%$ and $43 \%$ from observations in the high northern 340 latitudes $\left(42^{\circ} \mathrm{N}-76^{\circ} \mathrm{N}\right)$, respectively (Korolev et al. 2017,2003 ). At $-30^{\circ}$ to $-10^{\circ} \mathrm{C}, 1-\mathrm{Hz}$ 341 observations from the ORCAS campaign show lower mixed phase frequencies $(3 \%-5 \%)$ than 342 those in previous studies of Arctic clouds (13\% - 17\%) (Korolev et al. 2017, 2003) (Table S4).

Figure 6 shows the observed geometric means of LWC, IWC, $\mathrm{Nc}_{\text {liq }}$ and $\mathrm{Nc}_{\text {ice }}$ at $5^{\circ} \mathrm{C}$ 344 intervals from $-40^{\circ}-0^{\circ} \mathrm{C}$ for respective cloud phases. For liquid and mixed phases, Obs- $1 \mathrm{~s}$ data 345 show larger averaged quantities by 1-2 orders of magnitude compared with the coarser resolution 346 data, since the spatial averaged segments may include both in-cloud and clear-sky conditions. For 347 ice phase, Obs-200s data show larger IWC and $\mathrm{Nc}_{\text {ice }}$ than Obs-1s data, likely due to the restriction 348 of no more than $10 \%$ of missing values in the spatial averaging, which only allows relatively long, 349 continuous in-cloud segments that are often associated with higher IWC and $\mathrm{Nc}_{\text {ice }}$ to be used in 350 Obs-200s data. Trends in the averaged quantities with respect to temperature are generally similar 351 among various scales of observations, except for one temperature bin of $-30^{\circ}--25^{\circ} \mathrm{C}$ in mixed 352 phase likely due to the smaller sample sizes (Figure S7). For Obs-1s data, LWC and IWC generally 353 decrease with decreasing temperature for all cloud phases. For Obs-200s data, the average IWC 354 and $\mathrm{Nc}_{\text {ice }}$ are 1-2 orders of magnitude higher in ice phase compared with mixed phase, whereas 355 the average $\mathrm{LWC}$ and $\mathrm{Nc}_{\text {liq }}$ are 3-10 times higher in mixed phase than liquid phase at $-10^{\circ}-0^{\circ} \mathrm{C}$ 356 but more similar at other temperatures. For both liquid and mixed phases, average $\mathrm{Nc}_{\text {liq }}$ slightly 357 increases with decreasing temperature at $-25^{\circ}$ to $0^{\circ} \mathrm{C}$, and it decreases with decreasing temperature 358 below $-25^{\circ} \mathrm{C}$. In comparison, the trends in average $\mathrm{Nc}_{\text {ice }}$ vary between mixed and ice phases. In 359 mixed phase, average $\mathrm{Nc}_{\text {ice }}$ decreases (increases) with decreasing temperature above (below) $36025^{\circ} \mathrm{C}$, while in ice phase, average $\mathrm{Nc}_{\text {ice }}$ increases with decreasing temperature. 
Figure 7 further compares the geometric means of IWC, $\mathrm{LWC}, \mathrm{Nc}_{\text {liq }}$ and $\mathrm{Nc}_{\text {ice }}$ between simulations and the Obs-200s data. For liquid phase, simulated average LWC values (i.e., 0.01$0.1 \mathrm{~g} \mathrm{~m}^{-3}$ ) are about one order of magnitude greater than the Obs-200s data, and are more comparable to those in Obs-1s. The average $\mathrm{Nc}_{\text {liq }}$ in liquid phase in CAM-domain data is about three times of that in the observations from $-20^{\circ}$ to $0^{\circ} \mathrm{C}$. Previously, shallow convective detrainment was found to be the main source of cloud liquid over the Southern Ocean (Kay et al. 2016a). Since the parameterization of shallow convective detrainment defines cloud ice mass fraction to be larger than 0.1 below $-8^{\circ} \mathrm{C}$, much fewer liquid phase samples (i.e., ice mass fraction $<0.1$ ) can exist below $-8^{\circ} \mathrm{C}$ in the simulations (Figure S8). Therefore these liquid phase samples are more likely contributed by shallow convection detrainment above $-8^{\circ} \mathrm{C}$ and by other moist physical processes (e.g., microphysics "MPDLIQ" and macrophysics "MACPDLIQ") below $-8^{\circ} \mathrm{C}$.

For mixed phase, the simulations consistently show lower LWC, IWC and $\mathrm{Nc}_{\text {liq }}$ than the Obs-200s data at $-25^{\circ}-0^{\circ} \mathrm{C}$ by a factor of $3-10$, while the simulated $\mathrm{Nc}_{\text {ice }}$ is much higher than the observations at $-25^{\circ}--5^{\circ} \mathrm{C}$ by a factor of $3-500$. The overestimation of $\mathrm{Nc}_{\text {ice }}$ in simulations is consistent with previous findings of the parameterization of Meyers et al. (1992) overestimating ice number concentrations (e.g., Liu et al. 2011; DeMott et al. 2010). Another main difference is seen for ice phase, where simulated IWC is $\sim 2$ orders of magnitude lower than Obs-200s data, suggesting that the simulated ice particles are unrealistically smaller than the observations at $-40^{\circ}-$ $-10^{\circ} \mathrm{C}$ since the $\mathrm{Nc}_{\text {ice }}$ values are similar at this temperature range. In contrast, ice-phase $\mathrm{Nc}_{\text {ice }}$ in the simulations is lower than observations by a factor of $5-30$ from $-10^{\circ}-0^{\circ} \mathrm{C}$, respectively, possibly due to insufficient secondary ice production and/or missing marine organic aerosols as ice nucleating particles (INPs) in the simulations, which can be important at that temperature range 
383

384

over the Southern Oceans. These findings of ice phase are unlikely affected by the sampling volume, since all the datasets have sufficient number of ice phase samples (Figure S8).

The statistical robustness of the comparisons is supported by the fact that all of the average quantities in Figure 7 show very similar results between CAM-collocated and CAM-domain data, which almost never differ by more than one order of magnitude for the same temperature bins. In addition, sensitivity tests show maximum differences of $33 \%(29 \%)$ and $57 \%(32 \%)$ in mass (number) concentrations of cloud liquid and cloud ice, respectively, due to different ranges of particle size distributions in observations and simulations (Table S3), which proves that the differences in the observed and simulated quantities by more than one order of magnitude cannot be all attributed to size range differences.

Average mass ratios of $\mathrm{LWC} C \mathrm{CWC}$ are shown at various temperatures for two categories: total in-cloud conditions and mixed phase only (Figure 8), and number of samples are shown in Figure S9. Compared with average LWC and IWC, the observed ratios of LWC/CWC only slightly increase with spatial averaging, because the mass ratios have cancelled out the effect of including more clear-sky conditions on larger averaging scales. Compared with Obs-200s data for total incloud conditions, simulations show lower (higher) LWC/CWC ratios by $0.1-0.3 \quad(0.2)$ at $-40^{\circ}--5^{\circ} \mathrm{C}\left(-5^{\circ}-0^{\circ} \mathrm{C}\right)$, due to the combined effects from overestimated LWC in liquid phase, underestimated LWC in mixed phase, and underestimated IWC in both ice and mixed phases in simulations (Figure 7). The underestimated LWC/CWC ratios for total in-cloud conditions in the simulations is consistent with the previous comparisons between CAM5 simulations and the GCM-oriented CALIPSO Cloud Product (Cesana and Chepfer 2013). On the other hand, the simulations show slightly higher LWC/CWC for mixed phase compared with observations at $-20^{\circ}-$ 
$405 \quad 0^{\circ} \mathrm{C}$. The differences between total in-cloud and mixed phase only conditions suggest that phase

406 partitioning parameterizations may need to be specified for different phases.

4073.3 Relative humidity distributions in relation to temperature and cloud fraction

RH distributions have large influences on the evolution of cloud condensates. Thus, it is

409 important to examine RH distributions in conjunction with cloud microphysical and macrophysical

410 properties. In particular, CAM5 calculates ice cloud fraction as a function of RHi (Gettelman et

411 al. 2010), highlighting the need for validating the RH distributions at various cloud fractions.

412 Probability density functions (PDFs) of RHliq (Figure 9) and RHice (Figure 10) are shown for all

413 cloud phases at various cloud fractions. As temperature decreases from $-20^{\circ}-0^{\circ} \mathrm{C}$ to $-40^{\circ}--20^{\circ} \mathrm{C}$,

414 the peak position of RHliq distribution shifts from around liquid saturation to lower values, in

415 addition to a broadening effect on the distributions. As cloud fraction decreases from $>0.9$ to $<0.1$,

416 the peak position of RHliq decreases from $100 \%$ to $\sim 85 \%$ at $-20^{\circ}-0^{\circ} \mathrm{C}$, and from $\sim 75 \%$ to $15 \%$ at

$417-40^{\circ}--20^{\circ} \mathrm{C}$, respectively.

The simulations agree well with the observations for RHliq between $-20^{\circ}-0^{\circ} \mathrm{C}$. However,

419 the simulations show higher frequencies of RHi between $105 \%$ and $115 \%$ than Obs-200s data for

420 cloud fraction $>0.9$ at all temperature ranges. In addition, the simulations show narrower RHliq

421 and RHi distributions compared with observations at cloud fractions of $0.1-0.9$, lacking the large

422 variabilities of RHliq distributions as seen in the observations. When restricting cloud fractions,

423 the spatial averaging has minimal impacts on RH PDFs, and the two sets of simulations agree well

424 with each other, which further demonstrates the robustness of such comparisons on RH PDFs using

425 datasets with different sample volumes. 
A layer normalized frequency distribution of RHi at various temperatures and cloud 427 fractions is shown for the Obs-200s and CAM-domain datasets (Figure 11). The RHi frequency is 428 calculated as the number of samples in each $1{ }^{\circ} \mathrm{C} \times 5 \%$ bin divided by the total number of samples

429 in each $1{ }^{\circ} \mathrm{C}$ interval. Previously, layer-normalized RHi frequency was analyzed for $-88^{\circ}--23^{\circ} \mathrm{C}$ 430 based on in situ observations from $68^{\circ} \mathrm{N}$ to $21^{\circ} \mathrm{S}$ in the UT/LS (Krämer et al. 2009). Here we 431 extend that previous work to $-67^{\circ}-0^{\circ} \mathrm{C}$ at higher southern latitudes. The differences of normalized 432 RHi frequency between the simulations and observations are also shown (Figure $11 \mathrm{~g}-\mathrm{i}$ ). For cloud 433 fraction $\geq 0.9$, Obs-200s data show the maximum RHi at $125 \%$. CAM-domain data show higher 434 maximum RHi but only for very few cases (Figure S10). For cloud fractions of 0.1-0.9, the 435 simulations underestimate the frequencies of $\mathrm{RHi}<90 \%$ and $>110 \%$ compared with the 436 observations. This further illustrates that the smaller variabilities of RH PDFs in the simulations 437 (as seen in Figures 9 and 10) are consistently shown at all the temperatures from $-67^{\circ} \mathrm{C}$ to $0^{\circ} \mathrm{C}$. At 438 low cloud fraction $(<0.1)$, the simulations underestimate the frequencies of relatively dry 439 conditions from $-60^{\circ}--50^{\circ} \mathrm{C}$ and underestimate the frequencies of moist conditions (near ice 440 saturation) from $-8^{\circ}-0^{\circ} \mathrm{C}$.

\subsection{RH distributions for liquid, mixed and ice phase conditions}

In this section, we further examine the influences of cloud phases on cumulative frequency 443 distributions (CFDs) of RHliq and RHi in Figures 12 and 13, respectively. This analysis is 444 restricted to cloud fraction $\geq 0.9$, and separated by $10^{\circ} \mathrm{C}$ intervals from $-40^{\circ}-0^{\circ} \mathrm{C}$. For observations 445 from $\sim 0.1-50 \mathrm{~km}$ scales, similar CFDs of RHliq are seen for liquid and mixed phases, all of which 446 are close to liquid saturation. For example, $98 \%, 90 \%$ and $64 \%$ of the Obs-10s mixed phase data 447 show RHliq $>90 \%$ at $-10^{\circ}-0^{\circ} \mathrm{C},-20^{\circ}--10^{\circ} \mathrm{C}$, and $-30^{\circ}--20^{\circ} \mathrm{C}$, respectively. This result is 448 consistent with the theoretical understanding that MPCs generally show RH near liquid saturation 
449 at steady-state conditions (Korolev and Mazin 2003). The slight deviation from liquid saturation

450 in liquid and mixed phases is consistent with previously reported inhomogeneities such as cloud

451 holes (Korolev and Isaac 2006). The simulations show nearly identical RHliq CFDs to

452 observations for liquid phase, except for a lack of liquid droplets for colder temperatures at $-40^{\circ}-$

$453-30^{\circ} \mathrm{C}$ (Figure $12 \mathrm{~d}$ ). For mixed phase, the CAM-domain data show remarkable similarities to

454 observations for RHliq CFDs at $-20^{\circ}-0^{\circ} \mathrm{C}$ (note that the CAM-collocated data have very few

455 samples at this condition), yet no mixed phase is shown in the simulations below $-30^{\circ} \mathrm{C}$.

456 The largest differences between the observations and simulations are seen in ice phase

457 particularly for $-30^{\circ}-0^{\circ} \mathrm{C}$ (Figure $12 \mathrm{i}-\mathrm{k}$ ), where both simulations underestimate the occurrence

458 frequencies of RHliq $<95 \%$ by a fraction of $0.2-0.4$. In fact, for ice phase, only $80 \%, 59 \%$ and $11 \%$

459 of the Obs-10s ice phase data show RHliq $>90 \%$ at $-10^{\circ}-0^{\circ} \mathrm{C},-20^{\circ}--10^{\circ} \mathrm{C}$, and $-30^{\circ}--20^{\circ} \mathrm{C}$,

460 respectively. These results indicate that even though $\mathrm{RH}$ is centered at liquid saturation in liquid

461 and mixed phase as low as $-30^{\circ} \mathrm{C}$ on the scale of $\sim 0.1-50 \mathrm{~km}$ with liquid mass fraction>0.1 and

462 cloud fraction $\geq 0.9$, such assumption is not applicable when $\mathrm{LWC} / \mathrm{CWC} \leq 0.1$. A similar deviation

463 from liquid saturation with increasing IWC/CWC ratio was reported previously (Korolev and Isaac

464 2008), and our results do not show significant impacts from spatial averaging due to the restriction

465 of cloud fraction $\geq 0.9$.

The CFDs of RHi also show large differences between observations and simulations for

467 ice phase (Figure 13), where simulations overestimate the frequency of ISS conditions at $-30^{\circ}-$ $4680^{\circ} \mathrm{C}$. Such discrepancy is possibly due to the assumption used in the ice microphysics 469 parameterization in CAM5 (Morrison and Gettelman 2008; Gettelman et al. 2010), that is, RH 470 values reach liquid saturation as long as liquid droplets coexist with ice particles, regardless of the 471 small mass fraction of liquid phase being present. Note that this assumption is accurate for most 
472 of the liquid and mixed phase samples (Figure $12 \mathrm{a}-\mathrm{c}$ and $\mathrm{e}-\mathrm{g}$ ), but as liquid mass fraction

473 decreases to below 0.1 , it becomes unlikely that the in-cloud conditions can reach a steady-state

474 condition close to liquid saturation when few droplets exist. For liquid and mixed phases, all of

475 the observations show increasing fractions of ISS and increasing magnitudes of maximum ISS

476 with decreasing temperature, which agree relatively well with the simulations. Such increasing

477 magnitudes of ISS are a result of the majority of liquid and mixed phases being around liquid

478 saturation, which leads to higher RHi as temperature decreases based on the Clausius-Clapeyron

479 equation.

In addition, two other model-observation differences are seen for ice phase. First, the

481 simulations underestimate the occurrence frequencies of ice subsaturation. At $-10^{\circ}-0^{\circ} \mathrm{C}$, the 482 observations show $\sim 60 \%$ of ice phase being subsaturated, whereas CAM-collocated and CAM483 domain show $\sim 25 \%$ and $\sim 10 \%$, respectively. The fact that simulations are characterized by lower 484 IWC (Figure $7 \mathrm{~g}$ ) combined with the lower frequencies of subsaturation for ice phase suggests that 485 the simulations may under-represent ice particles in subsaturated layers during sedimentation (as 486 illustrated in Figure 3), likely due to insufficient accretion rates and/or over-amplified sublimation 487 rates. Second, the simulations do not show any ISS greater than $10 \%$ for ice phase at $-40^{\circ}--30^{\circ} \mathrm{C}$ 488 (Figure $13 \mathrm{~L}$ ), which accounts for $\sim 15 \%$ of the samples in all the observations. The lower 489 frequency of high ISS at colder temperatures is likely affected by the RHi threshold for immersion 490 nucleation of ice particles in the ice microphysics parameterization (Liu et al. 2007; Liu and Penner $4912005)$.

$492 \quad 3.5$ Vertical profiles of ice supersaturation

Ice supersaturation is a key factor that directly affects ice particle growth, deposition and

494 sublimation, which is further examined in Figure 14. Three cases are examined at temperatures 
below $0^{\circ} \mathrm{C}$ : ISS at low cloud fraction $(<0.1)$, ISS at high cloud fraction $(\geq 0.6)$, and non-ISS (i.e., $\mathrm{RHi} \leq 100 \%)$ at high cloud fraction $(\geq 0.6)$. Frequencies are either normalized by all samples (ac), or normalized by the total number of the aforementioned three cases $(\mathrm{d}-\mathrm{f})$. Comparisons are only shown for the CAM-collocated data (different results for CAM-domain data are not shown), since ISS frequency is affected by local conditions such as vertical velocity, temperature, and existing hydrometeors.

Focusing on $-40^{\circ}-0^{\circ} \mathrm{C}$, Obs-200s and CAM-collocated data show similar profiles of ISS at low cloud fraction with a peak frequency between $-15^{\circ}$ and $-10^{\circ} \mathrm{C}$. The simulation also shows a decreasing trend in ISS frequency at high cloud fraction with decreasing temperature, consistent with the observations. However, the simulation shows higher frequencies of ISS at high cloud fraction, which is likely due to the model assumption of liquid saturation for the fraction of the grid box where liquid and ice phases coexist, as discussed in Section 3.4.

For temperatures below $-40^{\circ} \mathrm{C}$, the CAM-collocated data significantly overestimate the frequencies of ISS by $0.05-0.75$ compared with the observations for cloud fractions $\geq 0.6$ (Figure $14 \mathrm{~b}$ ). At temperatures below $-50^{\circ} \mathrm{C}$, the CAM-collocated data underestimate ISS frequency at cloud fractions $<0.1$. This result indicates that additional ISS needs to be allowed for clear-sky conditions rather than in-cloud conditions in CAM5 simulations at cirrus cloud regimes. The relative frequencies of these three cases further illustrate the increasing discrepancies between the observations and simulations with decreasing temperatures below $-40^{\circ} \mathrm{C}$ (Figure $14 \mathrm{~d}-\mathrm{f}$ ). Improvements are potentially needed for parameterizations of clear-sky ISS, ice nucleation condition and water vapor deposition in clouds.

\section{Conclusions and implications for climate simulations over the Southern Ocean}


In this study, cloud microphysical properties over the Southern Ocean $\left(50^{\circ} \mathrm{W}-92^{\circ} \mathrm{W}\right.$ and $30^{\circ} \mathrm{S}-75^{\circ} \mathrm{S}$ ) are examined based on in situ airborne measurements, and are compared with two sets of CAM5 simulations: one is nudged by the reanalysis meteorological conditions and collocated

520 with the aircraft flight track (CAM-collocated), and the other one is free-running (CAM-domain) 521 and contains all the gridded data within the latitudinal, longitudinal and pressure domain during 522 the ORCAS campaign. The two simulations primarily produce comparable results (Figures $4-13$ ) 523 (except for ISS frequency due to sensitivity to local thermodynamic and dynamical conditions), 524 suggesting statistical robustness for the analyses conducted in this work when comparing localized 525 samples with a larger set of samples.

Airborne measurements are averaged over various horizontal scales from $\sim 0.1$ to $50 \mathrm{~km}$, 527 in order to provide a scale-aware comparison with GCM simulations. For the analyses of cloud 528 phase occurrence frequency, RH PDFs and CFDs, and LWC/CWC ratios, the sensitivity to 529 horizontal resolution is very low, which demonstrates the consistency of these results at various 530 horizontal resolutions. Other microphysical properties, i.e., LWC, IWC, $\mathrm{Nc}_{\text {liq }}$ and $\mathrm{Nc}_{\text {ice, }}$ show $1-2$ 531 orders of magnitude lower values when averaged over the entire scale that includes both in-cloud 532 and clear-sky conditions. These sensitivity tests demonstrate the applicability of using in situ 533 observations to evaluate GCM simulations for cloud characteristics and RH distributions, which 534 also help to guide future comparisons of datasets at various spatial resolutions.

Several main differences between simulations and observations are identified. Liquid and 536 mixed phases are seen in Obs-1s data at low temperatures $\left(-40^{\circ}--30^{\circ} \mathrm{C}\right)$ with $3 \%$ and $4 \%$ 537 frequencies, respectively, which are missing in the simulations. SLW droplets are frequently 538 observed from $-20^{\circ}-0^{\circ} \mathrm{C}$, consistent with previous observations that frequently reported SLW in 539 this region (Morrison et al. 2011a; Chubb et al. 2013; Huang et al. 2012b), while the simulations 
540 show higher liquid phase and lower mixed phase frequencies at this temperature range.

541 Simulations also show higher (lower) LWC in liquid (mixed) phase, higher (lower) $\mathrm{Nc}_{\text {liq }}$ in liquid

542 (mixed) phase, lower IWC in both ice and mixed phases, higher (lower) $\mathrm{Nc}_{\text {ice }}$ below (above) $-5^{\circ} \mathrm{C}$

543 in mixed phase, and lower (higher) LWC/CWC ratios below (above) $-5^{\circ} \mathrm{C}$ for the total in-cloud

544 conditions. Biases of cloud microphysical properties vary with different cloud phases, indicating

545 that future observational constraints may need to be specified for different phases. Processes of

546 interest not only include the temperature function of phase partitioning such as that used in the

547 shallow convection scheme of Park and Bretherton (2009) and tested by Kay et al. (2016a) and

548 Frey and Kay (2017), but also include ice nucleation and vapor deposition rate during the WBF

549 process as tested by Tan and Storelvmo (2016).

$550 \quad$ A large amount of ice phase is observed at $-10^{\circ}-0^{\circ} \mathrm{C}$, consistent with Huang et al. (2017)

551 which found relatively high $\mathrm{Nc}_{\text {ice }}$ of small ice particles at $>-9^{\circ} \mathrm{C}$. In comparison, at $-5^{\circ}-0^{\circ} \mathrm{C}$,

552 simulations show smaller ice mass fraction (IWC/CWC) for total in-cloud conditions, potentially

553 due to the insufficient growth of ice particles by deposition and/or accretion. For mixed phase,

554 simulations show higher $\mathrm{Nc}_{\text {ice }}$ at $-40^{\circ}--5^{\circ} \mathrm{C}$ and lower $\mathrm{Nc}_{\text {ice }}$ at $-5^{\circ}-0^{\circ} \mathrm{C}$ compared with the

555 observations, with the former difference possibly due to ice nucleation parameterization and the

556 latter difference possibly due to insufficient secondary ice production or missing INPs at warmer

557 temperatures over the Southern Ocean. The lack of ice subsaturation in simulations is likely due

558 to too fast removal of ice particles during sedimentation into subsaturated conditions.

559 In-cloud RH is frequently observed at liquid saturation for liquid and mixed phases. This

560 feature can be a result of several processes, such as vapor diffusion from liquid to ice due to the

561 WBF process, and/or updraft vertical velocity on the order of $0.1-1 \mathrm{~m} \mathrm{~s}^{-1}$ that can potentially

562 sustain simultaneous growth of liquid droplets and ice particles (Korolev and Field 2008; Korolev 
563 2007; Fan et al. 2011; Korolev 2008). The similarity among various scales of averaged observation 564 datasets highlights the consistency of such findings when a sufficient amount of LWC exists (i.e., 565 LWC/CWC >0.1). However, larger deviations from liquid saturation are observed in ice phase (i.e.,

$566 \mathrm{LWC} / \mathrm{CWC} \leq 0.1)$ at various scales. These results suggest that the assumption of liquid saturation 567 for wherever liquid droplets exist (Morrison and Gettelman 2008) is not applicable when mass 568 fraction of LWC is low, even for coexisting liquid droplets and ice particles on $\sim 100 \mathrm{~m}$ scales. In 569 addition, the increasing deviations from liquid saturation with increasing ice mass fraction imply 570 that RH frequency distributions can serve as an indicator for estimating the dominant phase of 571 cloud condensates (i.e., SLW droplets or ice particles). Comparing RH distributions, simulations show smaller RH variability for partially cloudy 573 conditions (cloud fraction of 0.1-0.9), and overestimate (underestimate) ISS frequencies for cloud 574 fraction $\geq 0.6(<0.1)$ at $-67^{\circ}-0^{\circ} \mathrm{C}\left(<-40^{\circ} \mathrm{C}\right)$. In addition, ice cloud fraction in CAM5 is parameterized 575 by grid average $\mathrm{RHi}$ and other prescribed parameters (e.g., $\mathrm{RHi}_{\max }=1.1$ and $\mathrm{RHi}_{\min }=0.8$ ) 576 (Gettelman et al. 2010). In contrast, observations show larger variabilities of RHi at various cloud 577 fractions, especially with higher frequencies of $\mathrm{RHi}>110 \%$ and $<90 \%$ at cloud fraction $\geq 0.1$ 578 compared with simulations (Figure 11), which in part casts doubt on the simplification of 579 parameterizing ice cloud fraction as a function of the grid average RHi rather than local RHi. 580 Previously, the lack of RH variability was found to be a main cause of missing clouds in CAM5 581 simulations ( $\mathrm{Wu}$ et al. 2017), and the simulations often overlook water vapor spatial 582 heterogeneities that were ubiquitously shown in observations (Diao et al. 2014). Since RH is a key 583 parameter that links dynamical and thermodynamical conditions with cloud macro- and 584 microphysical properties, improving the subgrid parameterization of RH is not only helpful for 585 improving RH distributions, ISS frequencies and ice cloud fraction, but also could be a viable 
approach to represent the impacts of subgrid-scale processes (e.g., eddies and turbulence) that are crucial for maintaining SLW (Field et al. 2014; Hill et al. 2014; Korolev and Field 2008) and calculating the lifetime of MPCs (Korolev and Mazin 2003). For future work, dynamical

589 influences from vertical velocity, such as previously shown for Arctic and midlatitude MPCs 590 (Solomon et al. 2011; Morrison et al. 2011b; Korolev and Field 2008; Shupe et al. 2008; Morrison 591 and Pinto 2005; Naud et al. 2006), warrant more detailed investigation over the Southern Ocean.

\section{Acknowledgement}

M. Diao acknowledges the support of NSF grant AGS-1642291 and NSF Office of Polar

594 Program (OPP) grant 1744965. X. Liu and M. Wu acknowledge the NSF grant AGS-1642289. J. 595 D'Alessandro acknowledges the support of John P. and Anna Monteverdi Scholarship. This work 596 is based on part of the master thesis work of J. D’Alessandro at San Jose State University 597 (D’Alessandro 2018). The National Center for Atmospheric Research (NCAR) is sponsored by the 598 National Science Foundation (NSF). The GV operations, and cloud microphysics and state 599 parameter instruments were supported by the NSF Lower Atmosphere Observing Facilities and 600 NCAR Earth Observing Laboratory (EOL). The primary award supporting ORCAS science 601 activities was NSF Polar Programs Grant 1501993. The NSF ORCAS campaign dataset is publicly 602 available and can be accessed at: http://www.eol.ucar.edu/field_projects/orcas. The VCSEL 603 hygrometer and water vapor measurements were supported by M. Diao and S. Beaton. Fast-2DC 604 measurements received support from A. Bansemer and C. Webster. We thank the pilots, 605 mechanics, technicians, scientists, software engineers, and project managers of the NCAR EOL 606 Research Aviation Facility for their support in the field and in post-processing data. The authors 607 also thank the three reviewers for their helpful comments and suggestions. 


\section{References}

Abdul-Razzak, H., and S. J. Ghan, 2000: A parameterization of aerosol activation: 2. Multiple aerosol types. J. Geophys. Res. Atmos., 105, 6837-6844, doi:10.1029/1999JD901161. http://doi.wiley.com/10.1029/1999JD901161.

Ahn, E., Y. Huang, T. H. Chubb, D. Baumgardner, P. Isaac, M. de Hoog, S. T. Siems, and M. J. Manton, 2017: In situ observations of wintertime low-altitude clouds over the Southern Ocean. Q. J. R. Meteorol. Soc., 143, 1381-1394, doi:10.1002/qj.3011. http://doi.wiley.com/10.1002/qj.3011.

Anderson, J. L., and Coauthors, 2004: The New GFDL Global Atmosphere and Land Model AM2-LM2: Evaluation with Prescribed SST Simulations. J. Clim., 17, 4641-4673, doi:10.1175/JCLI-3223.1. http://journals.ametsoc.org/doi/abs/10.1175/JCLI-3223.1.

Baumgardner, D., and Coauthors, 2017: Cloud Ice Properties: In Situ Measurement Challenges. Meteorol. Monogr., 58, 9.1-9.23, doi:10.1175/AMSMONOGRAPHS-D-16-0011.1.

Bergeron, T., 1928: Über die dreidimensional verknüpfende Wetteranalyse. Geophys. Norv., 5, $1-111$.

_ 1935: On the physics of clouds and precipitation. Proces Verbaux l'Association Météorologie, Int. Union Geod. Geophys., 156-178.

Biter, C. J., J. E. Dye, D. Huffman, and W. D. King, 1987: The Drop-Size Response of the CSIRO Liquid Water Probe. J. Atmos. Ocean. Technol., 4, 359-367, doi:10.1175/15200426(1987)004<0359:TDSROT>2.0.CO;2.

Bodas-Salcedo, A., K. D. Williams, P. R. Field, and A. P. Lock, 2012: The Surface Downwelling 
632

Solar Radiation Surplus over the Southern Ocean in the Met Office Model: The Role of Midlatitude Cyclone Clouds. J. Clim., 25, 7467-7486, doi:10.1175/JCLI-D-11-00702.1. http://journals.ametsoc.org/doi/abs/10.1175/JCLI-D-11-00702.1.

— , and Coauthors, 2014: Origins of the Solar Radiation Biases over the Southern Ocean in CFMIP2 Models*. J. Clim., 27, 41-56, doi:10.1175/JCLI-D-13-00169.1. http://journals.ametsoc.org/doi/abs/10.1175/JCLI-D-13-00169.1.

$\longrightarrow$, P. G. Hill, K. Furtado, K. D. Williams, P. R. Field, J. C. Manners, P. Hyder, and S. Kato, 2016: Large Contribution of Supercooled Liquid Clouds to the Solar Radiation Budget of the Southern Ocean. J. Clim., 29, 4213-4228, doi:10.1175/JCLI-D-15-0564.1. http://journals.ametsoc.org/doi/10.1175/JCLI-D-15-0564.1.

Brown, P. R. A., and P. N. Francis, 1995: Improved Measurements of the Ice Water Content in Cirrus Using a Total-Water Probe. J. Atmos. Ocean. Technol., 12, 410-414, doi:10.1175/1520-0426(1995)012<0410:IMOTIW>2.0.CO;2. http://journals.ametsoc.org/doi/abs/10.1175/15200426(1995)012\%3C0410\%3AIMOTIW\%3E2.0.CO\%3B2.

Ceppi, P., M. D. Zelinka, and D. L. Hartmann, 2014: The response of the Southern Hemispheric eddy-driven jet to future changes in shortwave radiation in CMIP5. Geophys. Res. Lett., 41, 3244-3250, doi:10.1002/2014GL060043. http://doi.wiley.com/10.1002/2014GL060043.

Cesana, G., and H. Chepfer, 2013: Evaluation of the cloud thermodynamic phase in a climate model using CALIPSO-GOCCP. J. Geophys. Res. Atmos., 118, 7922-7937, doi:10.1002/jgrd.50376. http://doi.wiley.com/10.1002/jgrd.50376.

Cesana, G., D. E. Waliser, X. Jiang, and J.-L. F. Li, 2015: Multimodel evaluation of cloud phase 
transition using satellite and reanalysis data. J. Geophys. Res. Atmos., 120, 7871-7892, doi:10.1002/2014JD022932. http://doi.wiley.com/10.1002/2014JD022932.

— , and Coauthors, 2016: Using in situ airborne measurements to evaluate three cloud phase products derived from CALIPSO. J. Geophys. Res. Atmos., 121, 5788-5808, doi:10.1002/2015JD024334. http://doi.wiley.com/10.1002/2015JD024334.

Cho, H.-M., S. L. Nasiri, and P. Yang, 2009: Application of CALIOP Measurements to the Evaluation of Cloud Phase Derived from MODIS Infrared Channels. J. Appl. Meteorol. Climatol., 48, 2169-2180, doi:10.1175/2009JAMC2238.1. http://journals.ametsoc.org/doi/abs/10.1175/2009JAMC2238.1.

Chubb, T. H., J. B. Jensen, S. T. Siems, and M. J. Manton, 2013: In situ observations of supercooled liquid clouds over the Southern Ocean during the HIAPER Pole-to-Pole Observation campaigns. Geophys. Res. Lett., 40, 5280-5285, doi:10.1002/grl.50986. http://doi.wiley.com/10.1002/grl.50986.

Chylek, P., and C. Borel, 2004: Mixed phase cloud water/ice structure from high spatial resolution satellite data. Geophys. Res. Lett., 31, L14104, doi:10.1029/2004GL020428. http://doi.wiley.com/10.1029/2004GL020428.

—, S. Robinson, M. K. Dubey, M. D. King, Q. Fu, and W. B. Clodius, 2006: Comparison of near-infrared and thermal infrared cloud phase detections. J. Geophys. Res., 111, D20203, doi:10.1029/2006JD007140. http://doi.wiley.com/10.1029/2006JD007140.

Costa, A., and Coauthors, 2017: Classification of Arctic, midlatitude and tropical clouds in the mixed-phase temperature regime. Atmos. Chem. Phys., 17, 12219-12238, doi:10.5194/acp17-12219-2017. https://www.atmos-chem-phys.net/17/12219/2017/. 
673 Cotton, W. R., G. J. Tripoli, R. M. Rauber, and E. A. Mulvihill, 1986: Numerical Simulation of

674

675

676

677

678

679

680

681

682

683

684

685

686

687

688

689

690

691

692

693

694

the Effects of Varying Ice Crystal Nucleation Rates and Aggregation Processes on

Orographic Snowfall. J. Clim. Appl. Meteorol., 25, 1658-1680, doi:10.1175/1520-

0450(1986)025<1658:NSOTEO>2.0.CO;2.

http://journals.ametsoc.org/doi/abs/10.1175/1520-

0450\%281986\%29025\%3C1658\%3ANSOTEO\%3E2.0.CO\%3B2.

D’Alessandro, J., 2018: Cloud Microphysical Properties based on Airborne In Situ Observations and Evaluation of a Weather Forecasting Model and a Global Climate Model. M.S. thesis, Dept. of Meteorology and Climate Science, San Jose State University, 78 pp. https://scholarworks.sjsu.edu/etd_theses/4935.

DeMott, P. J., and Coauthors, 2010: Predicting global atmospheric ice nuclei distributions and their impacts on climate. Proc. Natl. Acad. Sci. U. S. A., 107, 11217-11222, doi:10.1073/pnas.0910818107. http://www.pnas.org/content/107/25/11217.

Diao, M., L. Jumbam, J. Sheffield, E. F. Wood, and M. A. Zondlo, 2013: Validation of AIRS/AMSU-A water vapor and temperature data with in situ aircraft observations from the surface to UT/LS from $87^{\circ} \mathrm{N}-67^{\circ} \mathrm{S}$. J. Geophys. Res. Atmos., 118, 6816-6836, doi:10.1002/jgrd.50483.

, M. A. Zondlo, A. J. Heymsfield, L. M. Avallone, M. E. Paige, S. P. Beaton, T. Campos, and D. C. Rogers, 2014: Cloud-scale ice-supersaturated regions spatially correlate with high water vapor heterogeneities. Atmos. Chem. Phys., 14, 2639-2656, doi:10.5194/acp-142639-2014. http://www.atmos-chem-phys.net/14/2639/2014/.

Donner, L. J., and Coauthors, 2011: The Dynamical Core, Physical Parameterizations, and Basic 
Simulation Characteristics of the Atmospheric Component AM3 of the GFDL Global Coupled Model CM3. J. Clim., 24, 3484-3519, doi:10.1175/2011JCLI3955.1. http://journals.ametsoc.org/doi/abs/10.1175/2011JCLI3955.1.

Fan, J., S. Ghan, M. Ovchinnikov, X. Liu, P. J. Rasch, and A. Korolev, 2011: Representation of Arctic mixed-phase clouds and the Wegener-Bergeron-Findeisen process in climate models: Perspectives from a cloud-resolving study. J. Geophys. Res., 116, D00T07, doi:10.1029/2010JD015375. http://doi.wiley.com/10.1029/2010JD015375.

Field, P. R., R. J. Hogan, P. R. A. Brown, A. J. Illingworth, T. W. Choularton, P. H. Kaye, E. Hirst, and R. Greenaway, 2004: Simultaneous radar and aircraft observations of mixedphase cloud at the $100 \mathrm{~m}$ scale. Q. J. R. Meteorol. Soc., 130, 1877-1904, doi:10.1256/qj.03.102. http://doi.wiley.com/10.1256/qj.03.102.

Field, P. R., A. A. Hill, K. Furtado, and A. Korolev, 2014: Mixed-phase clouds in a turbulent environment. Part 2: Analytic treatment. Q. J. R. Meteorol. Soc., 140, 870-880, doi:10.1002/qj.2175. http://doi.wiley.com/10.1002/qj.2175.

Findeisen, W., 1938: Kolloid-meteorologische Vorgänge bei Neiderschlags-bildung. Meteorol. Zeitschrift, 55, 121-133.

—, 1940: On the origin of thunderstorm electricity. Meteorol. Zeitschrift, 57, 201-215.

Forbes, R. M., and M. Ahlgrimm, 2014: On the Representation of High-Latitude Boundary Layer Mixed-Phase Cloud in the ECMWF Global Model. Mon. Weather Rev., 142, 34253445, doi:10.1175/MWR-D-13-00325.1. http://journals.ametsoc.org/doi/10.1175/MWR-D13-00325.1. 
Frey, W. R., and J. E. Kay, 2017: The influence of extratropical cloud phase and amount feedbacks on climate sensitivity. Clim. Dyn., 1-20, doi:10.1007/s00382-017-3796-5. http://link.springer.com/10.1007/s00382-017-3796-5.

Fu, Q., and S. Hollars, 2004: Testing Mixed-Phase Cloud Water Vapor Parameterizations with SHEBA/FIRE-ACE Observations. J. Atmos. Sci., 61, 2083-2091, doi:10.1175/15200469(2004)061<2083:TMCWVP>2.0.CO;2. http://journals.ametsoc.org/doi/abs/10.1175/15200469\%282004\%29061\%3C2083\%3ATMCWVP\%3E2.0.CO\%3B2.

Gayet, J.-F., and Coauthors, 2006: Microphysical and optical properties of midlatitude cirrus clouds observed in the Southern hemisphere during INCA. Q. J. R. Meteorol. Soc., 132, 2719-2748, doi:10.1256/qj.05.162. http://doi.wiley.com/10.1256/qj.05.162.

Gettelman, A., and H. Morrison, 2015: Advanced two-moment bulk microphysics for global models. Part I: Off-line tests and comparison with other schemes. J. Clim., 28, 1268-1287, doi:10.1175/JCLI-D-14-00102.1. http://journals.ametsoc.org/doi/abs/10.1175/JCLI-D-1400102.1.

—, and S. C. Sherwood, 2016: Processes Responsible for Cloud Feedback. Curr. Clim. Chang. Reports, 2, 179-189, doi:10.1007/s40641-016-0052-8. http://link.springer.com/10.1007/s40641-016-0052-8.

Gettelman, A., E. J. Fetzer, A. Eldering, and F. W. Irion, 2006: The Global Distribution of Supersaturation in the Upper Troposphere from the Atmospheric Infrared Sounder. J. Clim., 19, 6089-6103, doi:10.1175/JCLI3955.1. http://journals.ametsoc.org/doi/abs/10.1175/JCLI3955.1. 
738

739

740

741

742

743

744

745

746

747

748

749

750

751

752

753

754

755

756

757

758

Gettelman, A., and Coauthors, 2010: Global simulations of ice nucleation and ice supersaturation with an improved cloud scheme in the Community Atmosphere Model. J. Geophys. Res., 115, D18216, doi:10.1029/2009JD013797. http://doi.wiley.com/10.1029/2009JD013797.

Goff, J. A., and S. Gratch, 1946: Low-pressure properties of water from -160 to 212 F. Trans. Am. Soc. Heat. Air-Cond. Eng., 52, 95-122.

Goloub, P., M. Herman, H. Chepfer, J. Riedi, G. Brogniez, P. Couvert, and G. Séze, 2000: Cloud thermodynamical phase classification from the POLDER spaceborne instrument. $J$. Geophys. Res. Atmos., 105, 14747-14759, doi:10.1029/1999JD901183. http://doi.wiley.com/10.1029/1999JD901183.

Govekar, P. D., C. Jakob, and J. Catto, 2014: The relationship between clouds and dynamics in Southern Hemisphere extratropical cyclones in the real world and a climate model. $J$. Geophys. Res. Atmos., 119, 6609-6628, doi:10.1002/2013JD020699. http://doi.wiley.com/10.1002/2013JD020699.

Hill, A. A., P. R. Field, K. Furtado, A. Korolev, and B. J. Shipway, 2014: Mixed-phase clouds in a turbulent environment. Part 1: Large-eddy simulation experiments. Q. J. R. Meteorol. Soc., 140, 855-869, doi:10.1002/qj.2177. http://doi.wiley.com/10.1002/qj.2177.

Hoskins, B. J., and K. I. Hodges, 2005: A New Perspective on Southern Hemisphere Storm Tracks. J. Clim., 18, 4108-4129, doi:10.1175/JCLI3570.1.

Hu, Y., and Coauthors, 2009: CALIPSO/CALIOP Cloud Phase Discrimination Algorithm. J. Atmos. Ocean. Technol., 26, 2293-2309, doi:10.1175/2009JTECHA1280.1. http://journals.ametsoc.org/doi/abs/10.1175/2009JTECHA1280.1. 
770

771

772

773

774

— , S. Rodier, K. Xu, W. Sun, J. Huang, B. Lin, P. Zhai, and D. Josset, 2010: Occurrence, liquid water content, and fraction of supercooled water clouds from combined CALIOP/IIR/MODIS measurements. J. Geophys. Res., 115, D00H34, doi:10.1029/2009JD012384. http://doi.wiley.com/10.1029/2009JD012384.

Huang, Y., S. T. Siems, M. J. Manton, L. B. Hande, and J. M. Haynes, 2012a: The Structure of Low-Altitude Clouds over the Southern Ocean as Seen by CloudSat. J. Clim., 25, 25352546, doi:10.1175/JCLI-D-11-00131.1. http://journals.ametsoc.org/doi/abs/10.1175/JCLID-11-00131.1.

,,,--- A. Protat, and J. Delanoë, 2012b: A study on the low-altitude clouds over the Southern Ocean using the DARDAR-MASK. J. Geophys. Res. Atmos., 117, doi:10.1029/2012JD017800.

,,--- , and G. Thompson, 2014: An Evaluation of WRF Simulations of Clouds over the Southern Ocean with A-Train Observations. Mon. Weather Rev., 142, 647-667, doi:10.1175/MWR-D-13-00128.1. http://journals.ametsoc.org/doi/abs/10.1175/MWR-D-1300128.1?journalCode=mwre.

—, C. N. Franklin, S. T. Siems, M. J. Manton, T. Chubb, A. Lock, S. Alexander, and A. Klekociuk, 2015: Evaluation of boundary-layer cloud forecasts over the Southern Ocean in a limited-area numerical weather prediction system using in situ, space-borne and groundbased observations. Q. J. R. Meteorol. Soc., 141, 2259-2276, doi:10.1002/qj.2519. http://doi.wiley.com/10.1002/qj.2519.

—_, T. Chubb, D. Baumgardner, M. DeHoog, S. T. Siems, and M. J. Manton, 2017: Evidence for secondary ice production in Southern Ocean open cellular convection. Q. J. R. Meteorol. 
Soc., 143, 1685-1703, doi:10.1002/qj.3041. http://doi.wiley.com/10.1002/qj.3041.

782 783

784 785

786 787 788 789 790 791

792 793

794 795 796 797 798 799 800 801 802

Jensen, J. B., S. Lee, P. B. Krummel, J. Katzfey, and D. Gogoasa, 2000: Precipitation in marine cumulus and stratocumulus.: Part I: Thermodynamic and dynamic observations of closed cell circulations and cumulus bands. Atmos. Res., 54, 117-155, doi:10.1016/S01698095(00)00040-5. https://www.sciencedirect.com/science/article/pii/S0169809500000405.

Kahn, B. H., A. Gettelman, E. J. Fetzer, A. Eldering, and C. K. Liang, 2009: Cloudy and clearsky relative humidity in the upper troposphere observed by the A-train. J. Geophys. Res., 114, D00H02, doi:10.1029/2009JD011738.

Kahn, B. H., S. L. Nasiri, M. M. Schreier, and B. A. Baum, 2011: Impacts of subpixel cloud heterogeneity on infrared thermodynamic phase assessment. J. Geophys. Res., 116, D20201, doi:10.1029/2011JD015774. http://doi.wiley.com/10.1029/2011JD015774.

Kay, J. E., and Coauthors, 2012: Exposing Global Cloud Biases in the Community Atmosphere Model (CAM) Using Satellite Observations and Their Corresponding Instrument Simulators. J. Clim., 25, 5190-5207, doi:10.1175/JCLI-D-11-00469.1. http://journals.ametsoc.org/doi/abs/10.1175/JCLI-D-11-00469.1.

Kay, J. E., and Coauthors, 2016a: Global Climate Impacts of Fixing the Southern Ocean Shortwave Radiation Bias in the Community Earth System Model (CESM). J. Clim., 29, 4617-4636, doi:10.1175/JCLI-D-15-0358.1. http://journals.ametsoc.org/doi/10.1175/JCLID-15-0358.1.

—, L. Bourdages, N. B. Miller, A. Morrison, V. Yettella, H. Chepfer, and B. Eaton, 2016b: Evaluating and improving cloud phase in the Community Atmosphere Model version 5 using spaceborne lidar observations. J. Geophys. Res. Atmos., 121, 4162-4176, 
804

805

806

807

808

809

810

811

812

813

814

815

816

817

818

819

820

821

822

823

King, W. D., D. A. Parkin, and R. J. Handsworth, 1978: A Hot-Wire Liquid Water Device Having Fully Calculable Response Characteristics. J. Appl. Meteorol., 17, 1809-1813, doi:10.1175/1520-0450(1978)017<1809:AHWLWD>2.0.CO;2.

Komurcu, M., and Coauthors, 2014: Intercomparison of the cloud water phase among global climate models. J. Geophys. Res. Atmos., 119, 3372-3400, doi:10.1002/2013JD021119. http://doi.wiley.com/10.1002/2013JD021119.

Korolev, A., 2007: Limitations of the Wegener-Bergeron-Findeisen Mechanism in the Evolution of Mixed-Phase Clouds. J. Atmos. Sci., 64, 3372-3375, doi:10.1175/JAS4035.1. http://journals.ametsoc.org/doi/abs/10.1175/JAS4035.1.

— , and G. A. Isaac, 2006: Relative Humidity in Liquid, Mixed-Phase, and Ice Clouds. J. Atmos. Sci., 63, 2865-2880, doi:10.1175/JAS3784.1.

— Considerations. J. Atmos. Sci., 65, 66-86, doi:10.1175/2007JAS2355.1. http://journals.ametsoc.org/doi/abs/10.1175/2007JAS2355.1.

Korolev, A., and Coauthors, 2017: Mixed-Phase Clouds: Progress and Challenges. Meteorol. Monogr., 58, 5.1-5.50, doi:10.1175/AMSMONOGRAPHS-D-17-0001.1. http://journals.ametsoc.org/doi/10.1175/AMSMONOGRAPHS-D-17-0001.1.

Korolev, A. V., 2008: Rates of phase transformations in mixed-phase clouds. Q. J. R. Meteorol. Soc., 134, 595-608, doi:10.1002/qj.230. http://doi.wiley.com/10.1002/qj.230.

, and I. P. Mazin, 2003: Supersaturation of Water Vapor in Clouds. J. Atmos. Sci., 60, 2957- 
825

826

827

828

829

830

831

832

833

834

835

836

837

838

839

840

841

842

843

844

_ and G. A. Isaac, 2008: The effect of spatial averaging on the relative humidity and phase composition of clouds. International Conference of Cloud Physics, Cancun http://cabernet.atmosfcu.unam.mx/ICCP2008/abstracts/Program_on_line/Poster_01/Korolev\&Isaac_extended.pdf.

- - - S. G. Cober, J. W. Strapp, and J. Hallett, 2003: Microphysical characterization of mixed-phase clouds. Q. J. R. Meteorol. Soc., 129, 39-65, doi:10.1256/qj.01.204. http://doi.wiley.com/10.1256/qj.01.204.

Krämer, M., and Coauthors, 2009: Ice supersaturations and cirrus cloud crystal numbers. Atmos. Chem. Phys., 9, 3505-3522, doi:10.5194/acp-9-3505-2009. http://www.atmos-chemphys.net/9/3505/2009/.

Lamarque, J.-F., and Coauthors, 2012: CAM-chem: description and evaluation of interactive atmospheric chemistry in the Community Earth System Model. Geosci. Model Dev., 5, 369-411, doi:10.5194/gmd-5-369-2012. http://www.geosci-model-dev.net/5/369/2012/.

Lamquin, N., C. J. Stubenrauch, K. Gierens, U. Burkhardt, and H. Smit, 2012: A global climatology of upper-tropospheric ice supersaturation occurrence inferred from the Atmospheric Infrared Sounder calibrated by MOZAIC. Atmos. Chem. Phys., 12, 381-405, doi:10.5194/acp-12-381-2012. http://www.atmos-chem-phys.net/12/381/2012/.

Lawson, R. P., and A. Gettelman, 2014: Impact of Antarctic mixed-phase clouds on climate. Proc. Natl. Acad. Sci. U. S. A., 111, 18156-18161, doi:10.1073/pnas.1418197111. http://www.ncbi.nlm.nih.gov/pubmed/25489069. 
861

862

863

864

865

866

Li, J.-L. F., D. E. Waliser, G. Stephens, S. Lee, T. L'Ecuyer, S. Kato, N. Loeb, and H.-Y. Ma, 2013: Characterizing and understanding radiation budget biases in CMIP3/CMIP5 GCMs, contemporary GCM, and reanalysis. J. Geophys. Res. Atmos., 118, 8166-8184, doi:10.1002/jgrd.50378.

Li, Z.-X., and H. Le Treut, 1992: Cloud-radiation feedbacks in a general circulation model and their dependence on cloud modelling assumptions. Clim. Dyn., 7, 133-139, doi:10.1007/BF00211155. http://link.springer.com/10.1007/BF00211155.

Lin, S.-J., 2004: A "Vertically Lagrangian” Finite-Volume Dynamical Core for Global Models. Mon. Weather Rev., 132, 2293-2307, doi:10.1175/15200493(2004)132<2293:AVLFDC>2.0.CO;2. http://journals.ametsoc.org/doi/abs/10.1175/15200493\%282004\%29132\%3C2293\%3AAVLFDC\%3E2.0.CO\%3B2.

Liu, X., and J. E. Penner, 2005: Ice nucleation parameterization for global models. Meteorol. Zeitschrift, 14, 499-514, doi:10.1127/0941-2948/2005/0059. http://openurl.ingenta.com/content/xref?genre=article\&issn=0941$2948 \&$ volume $=14 \&$ issue $=4 \&$ spage $=499$.

$\longrightarrow,-$ S. J. Ghan, and M. Wang, 2007: Inclusion of Ice Microphysics in the NCAR Community Atmospheric Model Version 3 (CAM3). J. Clim., 20, 4526-4547, doi:10.1175/JCLI4264.1. http://journals.ametsoc.org/doi/abs/10.1175/JCLI4264.1.

- and Coauthors, 2011: Testing cloud microphysics parameterizations in NCAR CAM5 with ISDAC and M-PACE observations. J. Geophys. Res., 116, D00T11, doi:10.1029/2011JD015889. http://doi.wiley.com/10.1029/2011JD015889. 
_ and Coauthors, 2012: Toward a minimal representation of aerosols in climate models: description and evaluation in the Community Atmosphere Model CAM5. Geosci. Model Dev., 5, 709-739, doi:10.5194/gmd-5-709-2012. http://www.geosci-modeldev.net/5/709/2012/.

Matus, A. V., and T. S. L'Ecuyer, 2017: The role of cloud phase in Earth's radiation budget. $J$. Geophys. Res. Atmos., 122, 2559-2578, doi:10.1002/2016JD025951. http://doi.wiley.com/10.1002/2016JD025951.

McCoy, D. T., D. L. Hartmann, D. P. Grosvenor, D. T. McCoy, D. L. Hartmann, and D. P. Grosvenor, 2014a: Observed Southern Ocean Cloud Properties and Shortwave Reflection. Part I: Calculation of SW Flux from Observed Cloud Properties*. J. Clim., 27, 8836-8857, doi:10.1175/JCLI-D-14-00287.1. http://journals.ametsoc.org/doi/abs/10.1175/JCLI-D-1400287.1.

$\longleftarrow,-,-,-,-$, and $-, 2014 \mathrm{~b}:$ Observed Southern Ocean Cloud Properties and Shortwave Reflection. Part II: Phase Changes and Low Cloud Feedback*. J. Clim., 27, 8858-8868, doi:10.1175/JCLI-D-14-00288.1. http://journals.ametsoc.org/doi/abs/10.1175/JCLI-D-14-00288.1.

—, I. Tan, D. L. Hartmann, M. D. Zelinka, and T. Storelvmo, 2016: On the relationships among cloud cover, mixed-phase partitioning, and planetary albedo in GCMs. $J$. $A d v$. Model. Earth Syst., 8, 650-668, doi:10.1002/2015MS000589. http://doi.wiley.com/10.1002/2015MS000589.

McFarquhar, G. M., G. Zhang, M. R. Poellot, G. L. Kok, R. McCoy, T. Tooman, A. Fridlind, and A. J. Heymsfield, 2007: Ice properties of single-layer stratocumulus during the Mixed- 
Phase Arctic Cloud Experiment: 1. Observations. J. Geophys. Res., 112, D24201, doi:10.1029/2007JD008633. http://doi.wiley.com/10.1029/2007JD008633.

Meyers, M. P., P. J. DeMott, and W. R. Cotton, 1992: New Primary Ice-Nucleation Parameterizations in an Explicit Cloud Model. J. Appl. Meteorol., 31, 708-721, doi:10.1175/1520-0450(1992)031<0708:NPINPI>2.0.CO;2. http://journals.ametsoc.org/doi/abs/10.1175/15200450(1992)031\%3C0708\%3ANPINPI\%3E2.0.CO\%3B2.

Mitchell, J. F. B., C. A. Senior, and W. J. Ingram, 1989: C02 and climate: a missing feedback? Nature, 341, 132-134, doi:10.1038/341132a0. http://www.nature.com/doifinder/10.1038/341132a0.

Morrison, A. E., S. T. Siems, M. J. Manton, and A. Nazarov, 2010: A Modeling Case Study of Mixed-Phase Clouds over the Southern Ocean and Tasmania. Mon. Weather Rev., 138, 839-862, doi:10.1175/2009MWR3011.1. http://journals.ametsoc.org/doi/abs/10.1175/2009MWR3011.1.

$\longrightarrow, \ldots$, and _ 2011a: A Three-Year Climatology of Cloud-Top Phase over the Southern Ocean and North Pacific. J. Clim., 24, 2405-2418, doi:10.1175/2010JCLI3842.1. http://journals.ametsoc.org/doi/abs/10.1175/2010JCLI3842.1.

Morrison, H., and J. O. Pinto, 2005: Mesoscale modeling of springtime Arctic mixed-phase stratiform clouds using a new two-moment bulk microphysics scheme. J. Atmos. Sci., 62 , 3683-3794. http://journals.ametsoc.org/doi/abs/10.1175/JAS3564.1.

— , and A. Gettelman, 2008: A New Two-Moment Bulk Stratiform Cloud Microphysics Scheme in the Community Atmosphere Model, Version 3 (CAM3). Part I: Description and 
Numerical Tests. J. Clim., 21, 3642-3659, doi:10.1175/2008JCLI2105.1. http://journals.ametsoc.org/doi/abs/10.1175/2008JCLI2105.1.

913 914 915 916 917 918 919 920 921 922 923 924 925 926 927 928 929 930 931 932

Murphy, D. M., and T. Koop, 2005: Review of the vapour pressures of ice and supercooled water for atmospheric applications. Q. J. R. Meteorol. Soc., 131, 1539-1565, doi:10.1256/qj.04.94. http://doi.wiley.com/10.1256/qj.04.94.

Nasiri, S. L., and B. H. Kahn, 2008: Limitations of Bispectral Infrared Cloud Phase Determination and Potential for Improvement. J. Appl. Meteorol. Climatol., 47, 2895-2910, doi:10.1175/2008JAMC1879.1. http://journals.ametsoc.org/doi/abs/10.1175/2008JAMC1879.1.

Naud, C. M., A. D. Del Genio, and M. Bauer, 2006: Observational Constraints on the Cloud Thermodynamic Phase in Midlatitude Storms. J. Clim., 19, 5273-5288, doi:10.1175/JCLI3919.1. http://journals.ametsoc.org/doi/abs/10.1175/JCLI3919.1.

Neale, R. B., and Coauthors, 2012: Description of the NCAR Community Atmosphere Model (CAM 5.0), NCAR/TN-486+STR. 1-274. http://www.cesm.ucar.edu/models/cesm1.0/cam/docs/description/cam5_desc.pdf (Accessed December 6, 2018).

Ovarlez, J., J.-F. Gayet, K. Gierens, J. Ström, H. Ovarlez, F. Auriol, R. Busen, and U. Schumann, 2002: Water vapour measurements inside cirrus clouds in Northern and Southern hemispheres during INCA. Geophys. Res. Lett., 29, 60-1-60-64, 
doi:10.1029/2001GL014440.

934

935

936

937

938

939

940

941

942

943

944

945

946

947

948

949

950

951

952

953

954

Park, S., and C. S. Bretherton, 2009: The University of Washington Shallow Convection and Moist Turbulence Schemes and Their Impact on Climate Simulations with the Community Atmosphere Model. J. Clim., 22, 3449-3469, doi:10.1175/2008JCLI2557.1. http://journals.ametsoc.org/doi/abs/10.1175/2008JCLI2557.1.

- - — , and P. J. Rasch, 2014: Integrating cloud processes in the Community Atmosphere Model, Version 5. J. Clim., 27, 6821-6856, doi:10.1175/JCLI-D-14-00087.1. http://journals.ametsoc.org/doi/abs/10.1175/JCLI-D-14-00087.1.

Rauber, R. M., and A. Tokay, 1991: An Explanation for the Existence of Supercooled Water at the Top of Cold Clouds. J. Atmos. Sci., 48, 1005-1023, doi:10.1175/15200469(1991)048<1005:AEFTEO>2.0.CO;2. http://journals.ametsoc.org/doi/abs/10.1175/15200469\%281991\%29048\%3C1005\%3AAEFTEO\%3E2.0.CO\%3B2.

Riedi, J., P. Goloub, and R. T. Marchand, 2001: Comparison of POLDER cloud phase retrievals to active remote sensors measurements at the ARM SGP site. Geophys. Res. Lett., 28, 2185-2188, doi:10.1029/2000GL012758. http://doi.wiley.com/10.1029/2000GL012758.

— , and Coauthors, 2010: Cloud thermodynamic phase inferred from merged POLDER and MODIS data. Atmos. Chem. Phys., 10, 11851-11865, doi:10.5194/acp-10-11851-2010. http://www.atmos-chem-phys.net/10/11851/2010/.

Rotstayn, L. D., B. F. Ryan, and J. J. Katzfey, 2000: A Scheme for Calculation of the Liquid Fraction in Mixed-Phase Stratiform Clouds in Large-Scale Models. Mon. Weather Rev., 128, 1070-1088, doi:10.1175/1520-0493(2000)128<1070:ASFCOT>2.0.CO;2. 
http://journals.ametsoc.org/doi/abs/10.1175/15200493\%282000\%29128\%3C1070\%3AASFCOT\%3E2.0.CO\%3B2.

Shupe, M. D., and J. M. Intrieri, 2004: Cloud Radiative Forcing of the Arctic Surface: The Influence of Cloud Properties, Surface Albedo, and Solar Zenith Angle. J. Clim., 17, 616628, doi:10.1175/1520-0442(2004)017<0616:CRFOTA>2.0.CO;2. http://journals.ametsoc.org/doi/abs/10.1175/15200442\%282004\%29017\%3C0616\%3ACRFOTA\%3E2.0.CO\%3B2.

— P. Kollias, P. O. G. Persson, and G. M. McFarquhar, 2008: Vertical Motions in Arctic Mixed-Phase Stratiform Clouds. J. Atmos. Sci., 65, 1304-1322, doi:10.1175/2007JAS2479.1. http://journals.ametsoc.org/doi/abs/10.1175/2007JAS2479.1.

Solomon, A., M. D. Shupe, P. O. G. Persson, and H. Morrison, 2011: Moisture and dynamical interactions maintaining decoupled Arctic mixed-phase stratocumulus in the presence of a humidity inversion. Atmos. Chem. Phys., 11, 10127-10148, doi:10.5194/acp-11-101272011. http://www.atmos-chem-phys.net/11/10127/2011/.

Spichtinger, P., K. Gierens, and W. Read, 2003: The global distribution of ice-supersaturated regions as seen by the Microwave Limb Sounder. Q. J. R. Meteorol. Soc., 129, 3391-3410, doi:10.1256/qj.02.141. http://doi.wiley.com/10.1256/qj.02.141.

Stephens, B. B., 2017: ORCAS Merge Products. Version 1.0. UCAR/NCAR - Earth Observing Laboratory. https://doi.org/10.5065/D6SB445X. (Accessed January 10, 2019).

Stephens, B. B., and Coauthors, 2018: The O2 /N2 Ratio and CO2 Airborne Southern Ocean Study. Bull. Am. Meteorol. Soc., 99, 381-402, doi:10.1175/BAMS-D-16-0206.1. http://journals.ametsoc.org/doi/10.1175/BAMS-D-16-0206.1. 
977 Sun, Z., and K. P. Shine, 1994: Studies of the radiative properties of ice and mixed-phase clouds.

978 Q. J. R. Meteorol. Soc., 120, 111-137, doi:10.1002/qj.49712051508.

979 http://doi.wiley.com/10.1002/qj.49712051508.

980 Tan, I., and T. Storelvmo, 2016: Sensitivity Study on the Influence of Cloud Microphysical

981 Parameters on Mixed-Phase Cloud Thermodynamic Phase Partitioning in CAM5. J. Atmos.

$982 \quad S c i ., 73,709-728$, doi:10.1175/JAS-D-15-0152.1.

983

http://journals.ametsoc.org/doi/10.1175/JAS-D-15-0152.1.

984

985

986

987

988

989

990

991

992

993

994

995

996

997

998

Tan, I., T. Storelvmo, and M. D. Zelinka, 2016: Observational constraints on mixed-phase clouds imply higher climate sensitivity. Science (80-. )., 352, 224-227, doi:10.1126/science.aad5300. http://science.sciencemag.org/content/352/6282/224.abstract.

Thompson, D. R., B. H. Kahn, R. O. Green, S. A. Chien, E. M. Middleton, and D. Q. Tran, 2018: Global spectroscopic survey of cloud thermodynamic phase at high spatial resolution, 2005-2015. Atmos. Meas. Tech., 11, 1019-1030, doi:10.5194/amt-11-1019-2018. https://www.atmos-meas-tech.net/11/1019/2018/.

Trenberth, K. E., and J. T. Fasullo, 2010: Simulation of Present-Day and Twenty-First-Century Energy Budgets of the Southern Oceans. J. Clim., 23, 440-454, doi:10.1175/2009JCLI3152.1.

Tsushima, Y., and Coauthors, 2006: Importance of the mixed-phase cloud distribution in the control climate for assessing the response of clouds to carbon dioxide increase: a multimodel study. Clim. Dyn., 27, 113-126, doi:10.1007/s00382-006-0127-7. http://link.springer.com/10.1007/s00382-006-0127-7.

Wang, Y., D. Zhang, X. Liu, and Z. Wang, 2018: Distinct Contributions of Ice Nucleation, 
Large-Scale Environment, and Shallow Cumulus Detrainment to Cloud Phase Partitioning With NCAR CAM5. J. Geophys. Res. Atmos., 123, 1132-1154, doi:10.1002/2017JD027213. http://doi.wiley.com/10.1002/2017JD027213.

1002 Wegener, A., 1911: Thermodynamik der Atmosphäre. J. A. Barth, 331 pp.

1003 Wu, C., X. Liu, M. Diao, K. Zhang, A. Gettelman, Z. Lu, J. E. J. E. Penner, and Z. Lin, 2017 :

1004 Direct comparisons of ice cloud macro- and microphysical properties simulated by the 1005 Community Atmosphere Model version 5 with HIPPO aircraft observations. Atmos. Chem. 1006 Phys., 17, 4731-4749, doi:10.5194/acp-17-4731-2017. http://www.atmos-chem$1007 \quad$ phys.net/17/4731/2017/.

1008 Zhang, K., and Coauthors, 2014: Technical Note: On the use of nudging for aerosol-climate 1009 model intercomparison studies. Atmos. Chem. Phys., 14, 8631-8645, doi:10.5194/acp-141010 8631-2014. http://www.atmos-chem-phys.net/14/8631/2014/.

1011 Zondlo, M. A., M. E. Paige, S. M. Massick, and J. A. Silver, 2010: Vertical cavity laser 1012 hygrometer for the National Science Foundation Gulfstream-V aircraft. J. Geophys. Res., 1013 115, D20309, doi:10.1029/2010JD014445. 
Table 1. Number of samples and occurrence frequencies $(\%)$ of three cloud phases at various

\begin{tabular}{|c|c|c|c|c|c|c|c|}
\hline \multirow[t]{2}{*}{ Dataset } & \multirow[t]{2}{*}{ Temperature } & \multicolumn{3}{|c|}{ CWC $\geq 0.01$ g m-3 } & \multicolumn{3}{|c|}{ Cloud fraction $\geq 0.6$} \\
\hline & & Liquid & Mixed & Ice & Liquid & Mixed & Ice \\
\hline \multirow[t]{4}{*}{ Obs-1s } & $-10^{\circ} \leq \mathrm{T}<0^{\circ} \mathrm{C}$ & $3114(34 \%)$ & $1530(17 \%)$ & $4414(49 \%)$ & $4245(41 \%)$ & $1602(16 \%)$ & $4465(43 \%)$ \\
\hline & $-20^{\circ} \leq \mathrm{T}<-10^{\circ} \mathrm{C}$ & $620(18 \%)$ & $176(5 \%)$ & $2687(77 \%)$ & $838(23 \%)$ & $182(5 \%)$ & $2629(72 \%)$ \\
\hline & $-30^{\circ} \leq \mathrm{T}<-20^{\circ} \mathrm{C}$ & $210(6 \%)$ & $114(3 \%)$ & $3406(91 \%)$ & $426(10 \%)$ & $117(3 \%)$ & $3672(87 \%)$ \\
\hline & $-40^{\circ} \leq \mathrm{T}<-30^{\circ} \mathrm{C}$ & $62(3 \%)$ & $81(4 \%)$ & $1663(92 \%)$ & $76(3 \%)$ & $82(3 \%)$ & $2209(93 \%)$ \\
\hline \multirow[t]{4}{*}{ Obs-10s } & $-10^{\circ} \leq \mathrm{T}<0^{\circ} \mathrm{C}$ & $2928(28 \%)$ & $2249(21 \%)$ & $5401(51 \%)$ & $3237(31 \%)$ & $2524(24 \%)$ & $4780(45 \%)$ \\
\hline & $-20^{\circ} \leq \mathrm{T}<-10^{\circ} \mathrm{C}$ & $634(16 \%)$ & $276(7 \%)$ & $3108(77 \%)$ & $659(18 \%)$ & $362(10 \%)$ & $2722(73 \%)$ \\
\hline & $-30^{\circ} \leq \mathrm{T}<-20^{\circ} \mathrm{C}$ & $180(5 \%)$ & $171(4 \%)$ & $3607(91 \%)$ & $233(5 \%)$ & $288(7 \%)$ & $3738(88 \%)$ \\
\hline & $-40^{\circ} \leq \mathrm{T}<-30^{\circ} \mathrm{C}$ & $28(2 \%)$ & $133(7 \%)$ & $1647(91 \%)$ & $38(2 \%)$ & $154(7 \%)$ & $2152(92 \%)$ \\
\hline \multirow[t]{4}{*}{ Obs-100s } & $-10^{\circ} \leq \mathrm{T}<0^{\circ} \mathrm{C}$ & $4332(30 \%)$ & $4492(31 \%)$ & $5772(40 \%)$ & $1057(12 \%)$ & $3722(41 \%)$ & $4228(47 \%)$ \\
\hline & $-20^{\circ} \leq \mathrm{T}<-10^{\circ} \mathrm{C}$ & $881(17 \%)$ & $850(16 \%)$ & $3454(67 \%)$ & $70(2 \%)$ & $262(9 \%)$ & $2507(88 \%)$ \\
\hline & $-30^{\circ} \leq \mathrm{T}<-20^{\circ} \mathrm{C}$ & $223(5 \%)$ & $204(4 \%)$ & $4261(91 \%)$ & $133(3 \%)$ & $115(3 \%)$ & $3708(94 \%)$ \\
\hline & $-40^{\circ} \leq \mathrm{T}<-30^{\circ} \mathrm{C}$ & $0(0 \%)$ & $205(9 \%)$ & $2007(91 \%)$ & $0(0 \%)$ & $142(7 \%)$ & $1760(93 \%)$ \\
\hline \multirow[t]{4}{*}{ Obs-200s * } & $-10^{\circ} \leq \mathrm{T}<0^{\circ} \mathrm{C}$ & $4653(27 \%)$ & $6186(37 \%)$ & $6098(36 \%)$ & $434(5 \%)$ & $3913(47 \%)$ & $4013(48 \%)$ \\
\hline & $-20^{\circ} \leq \mathrm{T}<-10^{\circ} \mathrm{C}$ & $969(16 \%)$ & $985(17 \%)$ & $3966(67 \%)$ & $0(0 \%)$ & $57(2 \%)$ & $2721(98 \%)$ \\
\hline & $-30^{\circ} \leq \mathrm{T}<-20^{\circ} \mathrm{C}$ & $250(5 \%)$ & $258(5 \%)$ & $4738(90 \%)$ & $10(0 \%)$ & $177(5 \%)$ & $3631(95 \%)$ \\
\hline & $-40^{\circ} \leq \mathrm{T}<-30^{\circ} \mathrm{C}$ & $0(0 \%)$ & $262(10 \%)$ & $2261(90 \%)$ & $0(0 \%)$ & $26(2 \%)$ & $1707(98 \%)$ \\
\hline \multirow{4}{*}{$\begin{array}{c}\text { CAM- } \\
\text { collocated }\end{array}$} & $-10^{\circ} \leq \mathrm{T}<0^{\circ} \mathrm{C}$ & $6599(60 \%)$ & $289(3 \%)$ & $4028(37 \%)$ & $4042(59 \%)$ & $173(3 \%)$ & $2689(39 \%)$ \\
\hline & $-20^{\circ} \leq \mathrm{T}<-10^{\circ} \mathrm{C}$ & $705(53 \%)$ & $18(1 \%)$ & $604(46 \%)$ & $700(18 \%)$ & $205(5 \%)$ & $2995(77 \%)$ \\
\hline & $-30^{\circ} \leq \mathrm{T}<-20^{\circ} \mathrm{C}$ & $0(0 \%)$ & $0(0 \%)$ & $978(100 \%)$ & $0(0 \%)$ & $0(0 \%)$ & $3315(100 \%)$ \\
\hline & $-40^{\circ} \leq \mathrm{T}<-30^{\circ} \mathrm{C}$ & $0(0 \%)$ & $0(0 \%)$ & $292(100 \%)$ & $0(0 \%)$ & $0(0 \%)$ & $2890(100 \%)$ \\
\hline \multirow{4}{*}{$\begin{array}{l}\text { CAM- } \\
\text { domain }\end{array}$} & $-10^{\circ} \leq \mathrm{T}<0^{\circ} \mathrm{C}$ & $112293(70 \%)$ & $6735(4 \%)$ & $40321(25 \%)$ & $84882(63 \%)$ & $4802(4 \%)$ & $45661(34 \%)$ \\
\hline & $-20^{\circ} \leq \mathrm{T}<-10^{\circ} \mathrm{C}$ & $5404(29 \%)$ & $195(1 \%)$ & $12793(70 \%)$ & $5564(6 \%)$ & $1236(1 \%)$ & $92236(93 \%)$ \\
\hline & $-30^{\circ} \leq \mathrm{T}<-20^{\circ} \mathrm{C}$ & $66(1 \%)$ & $3(<1 \%)$ & $12459(99 \%)$ & $28(<1 \%)$ & $32(<1 \%)$ & $72318(100 \%)$ \\
\hline & $-40^{\circ} \leq \mathrm{T}<-30^{\circ} \mathrm{C}$ & $0(0 \%)$ & $0(0 \%)$ & $10558(100 \%)$ & $0(0 \%)$ & $0(0 \%)$ & $54960(100 \%)$ \\
\hline
\end{tabular}

$1018 *$ The number of samples generally increases with increasing averaging scales of observation data

1019 for $\mathrm{CWC} \geq 0.01 \mathrm{~g} \mathrm{~m}^{-3}$, mostly due to the fact that this restriction can be more easily satisfied for 1020 averaged datasets. For example, the center second of the Obs-200s data does not need to be in- 
1021 cloud to have averaged $\mathrm{CWC} \geq 0.01 \mathrm{~g} \mathrm{~m}^{-3}$, while each second of Obs- $1 \mathrm{~s}$ data has to be in-cloud to 1022 satisfy this criterion. For Obs-1s data, cloud fraction is calculated for -5 to +4 seconds (a total of 102310 second) around each second in Table 1, Figures 5, 9, 10, 12 and 13. 


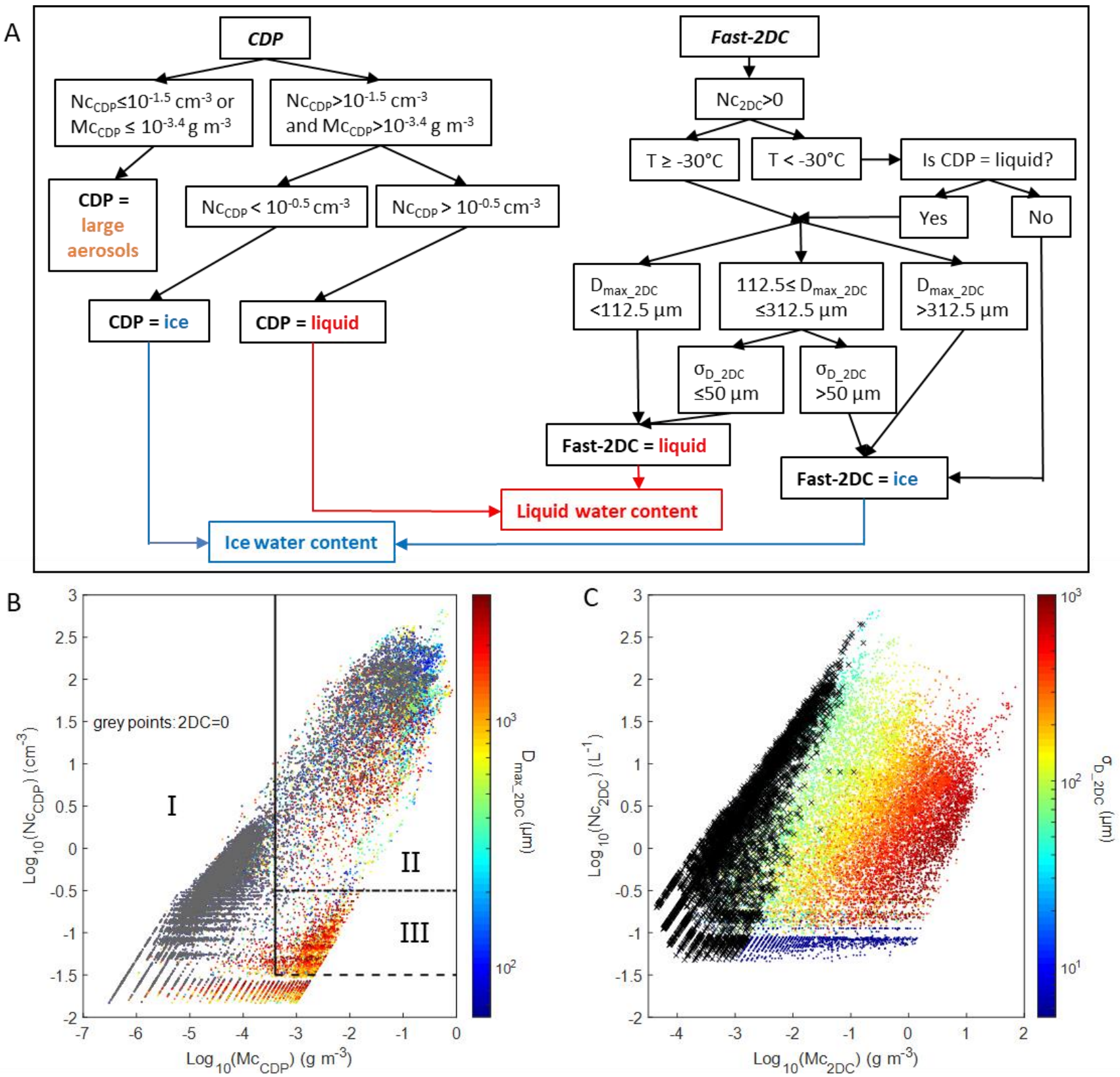

Figure 1. Cloud phase identification method used in this work. (a) A diagram for identifying ice

1026 and liquid phase samples from two probes separately, and the total IWC and LWC stand for the

1027 sum of IWC and LWC from two probes, respectively. (b) Number versus mass concentrations of

1028 CDP probe $\left(\mathrm{Nc}_{\mathrm{CDP}}\right.$ and $\mathrm{Mc}_{\mathrm{CDP}}$, respectively) color coded by $\mathrm{D}_{\text {max }}$ 2DC. Grey dots show $\mathrm{Nc}_{2 \mathrm{DC}}=0$.

1029 Section I, II, III are defined as large aerosols, liquid droplets and ice crystals, respectively. (c)

1030 Relationship of $\mathrm{Nc}_{2 \mathrm{DC}}$ and $\mathrm{Mc}_{2 \mathrm{DC}}$, color coded by the standard deviation of $1-\mathrm{Hz}$ particle size 
1031 distribution $\left(\sigma_{\mathrm{D}_{-} 2 \mathrm{DC}}\right)$. Black markers highlight where the Fast-2DC measurements are identified as 1032 liquid droplets. 
A

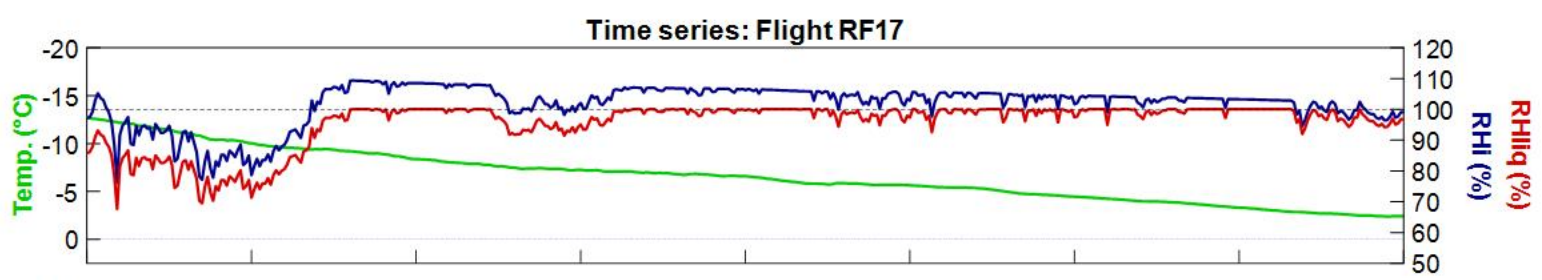

B

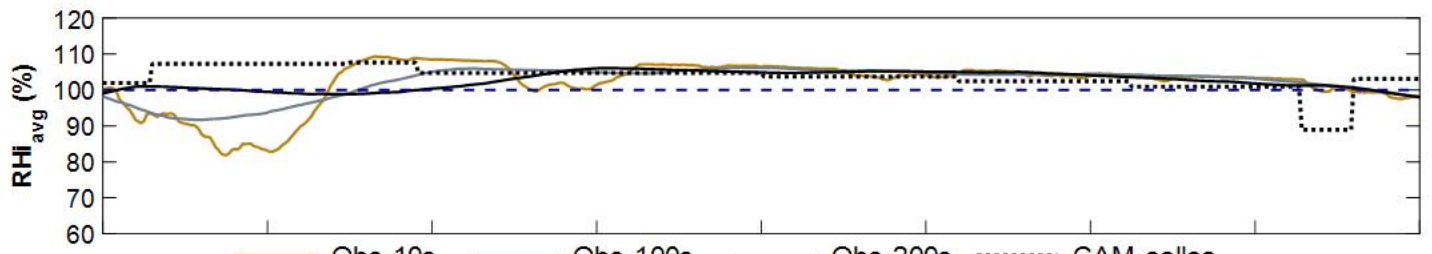

C

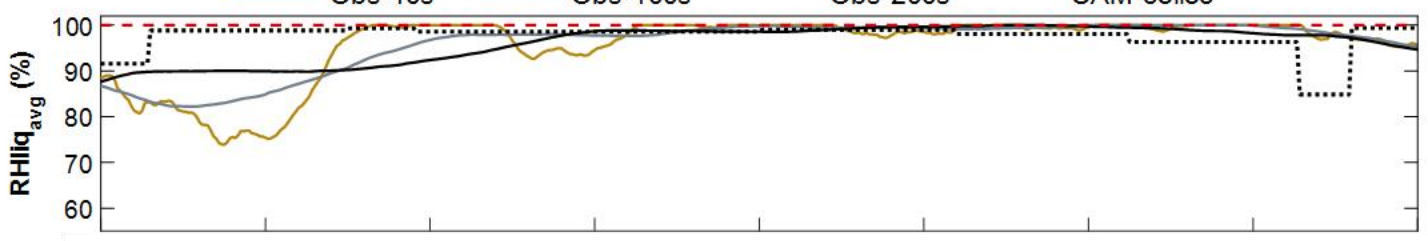

D

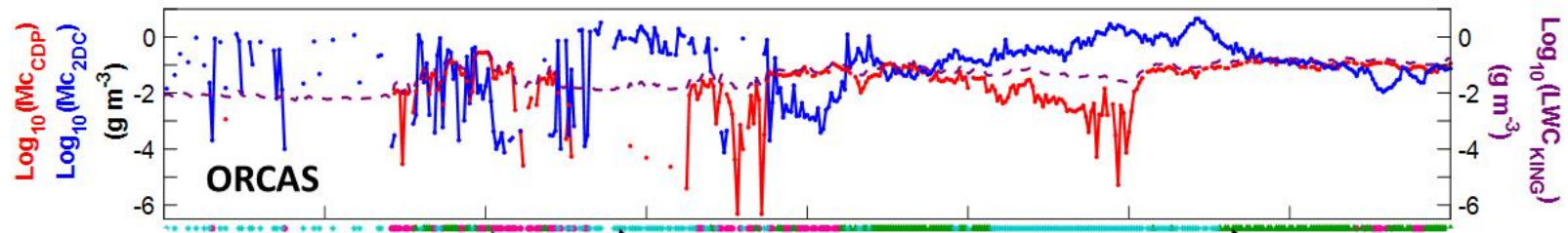

E

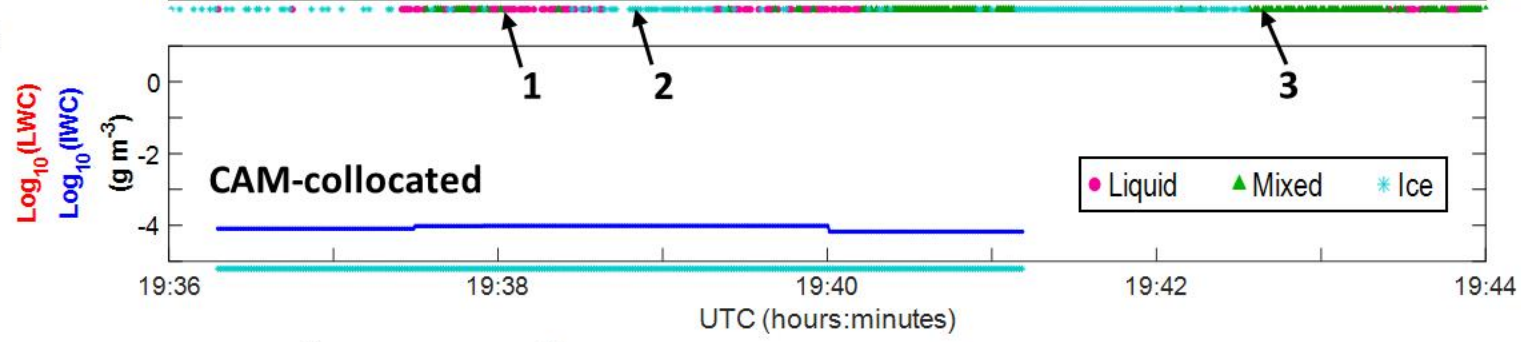

F

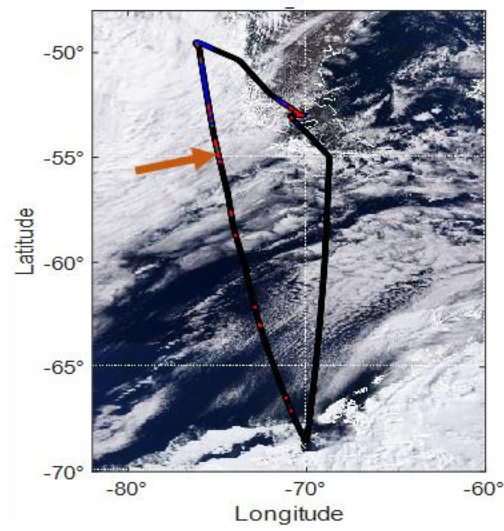

G
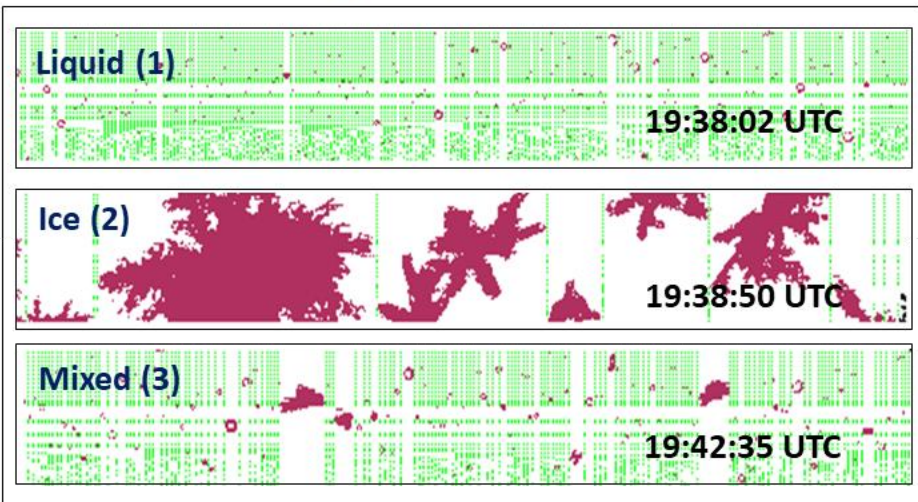

Figure 2. An example time series in Research Flight 17 (RF17) of the NSF ORCAS campaign. (a) 
1037 data; (d) log-scale $\mathrm{Mc}_{\mathrm{CDP}}$ (red) and $\mathrm{Mc}_{2 \mathrm{DC}}$ (blue) and LWC measured by the King probe (purple); 1038 (e) LWC and IWC from CAM-collocated data. In (d) and (e), cloud phases are identified by 1039 markers below the abscissa. (f) MODIS satellite images around the flight track (black), with cloud 1040 phase highlighted in colors and an orange arrow pointing at the time series segment. The MODIS 1041 satellite image is on February 24, 2016, UTC 19:10:00. (g) Cloud particle imageries from the Fast1042 2DC probe for the three individual seconds noted by black arrows 1-3, respectively. 
A

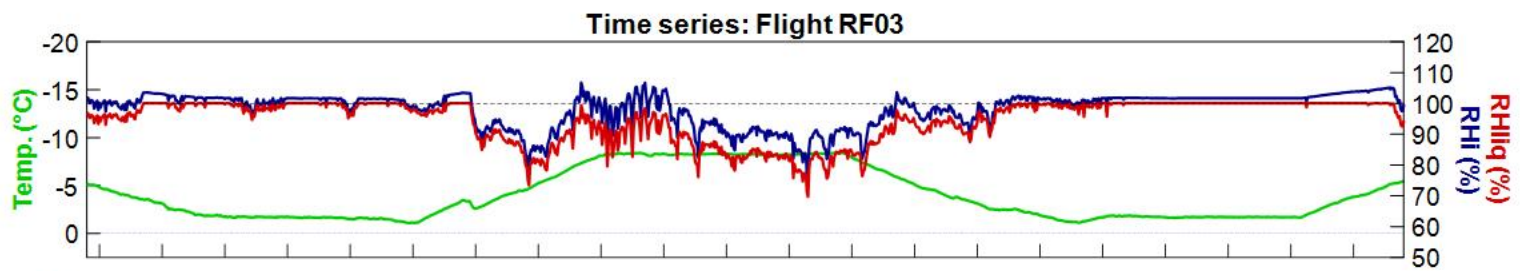

B

C
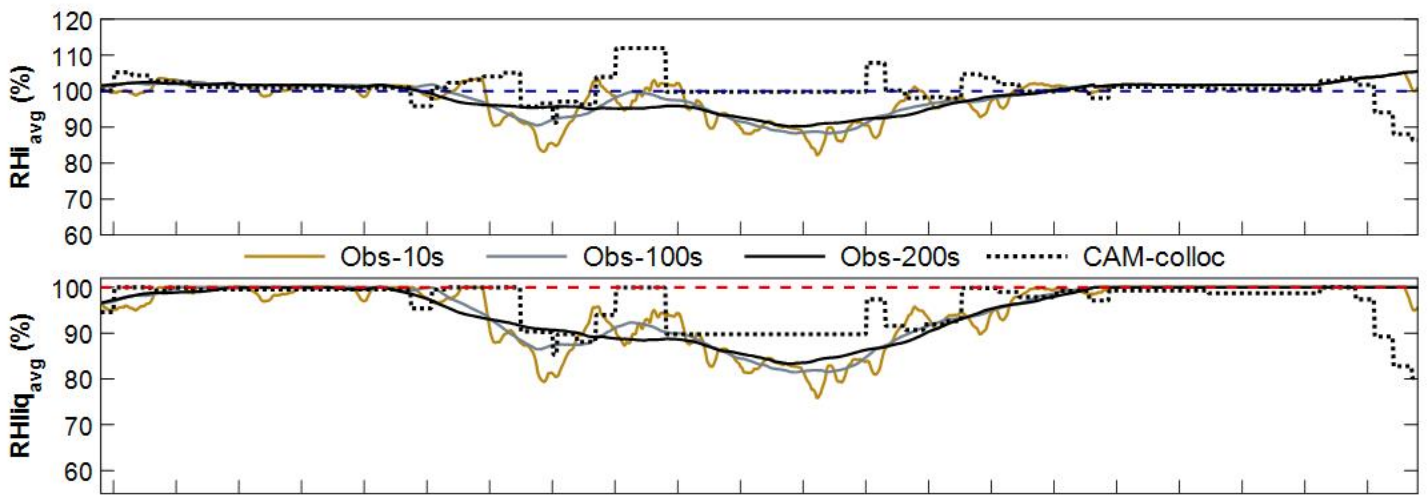

D

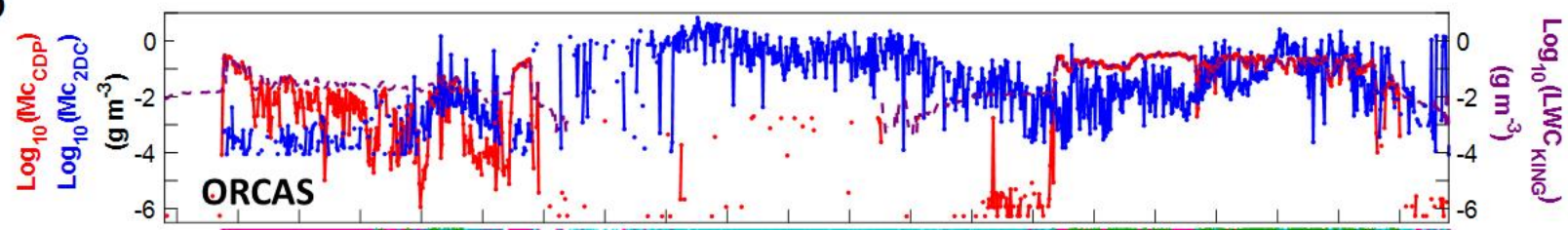

E

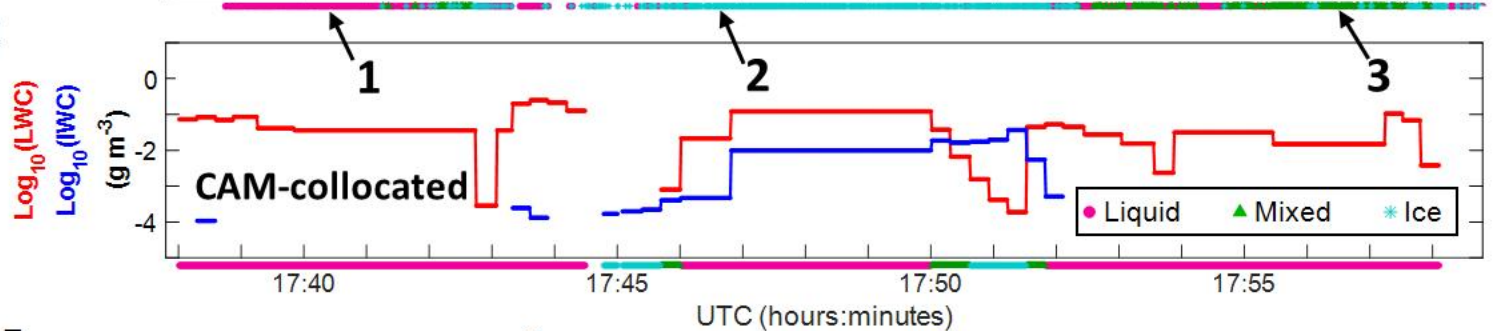

$\mathbf{F}$

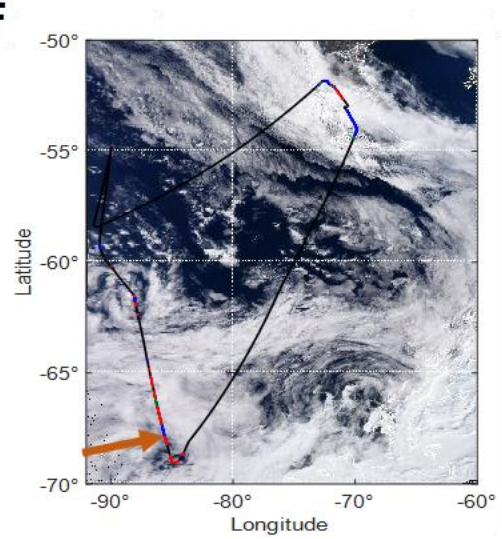

G

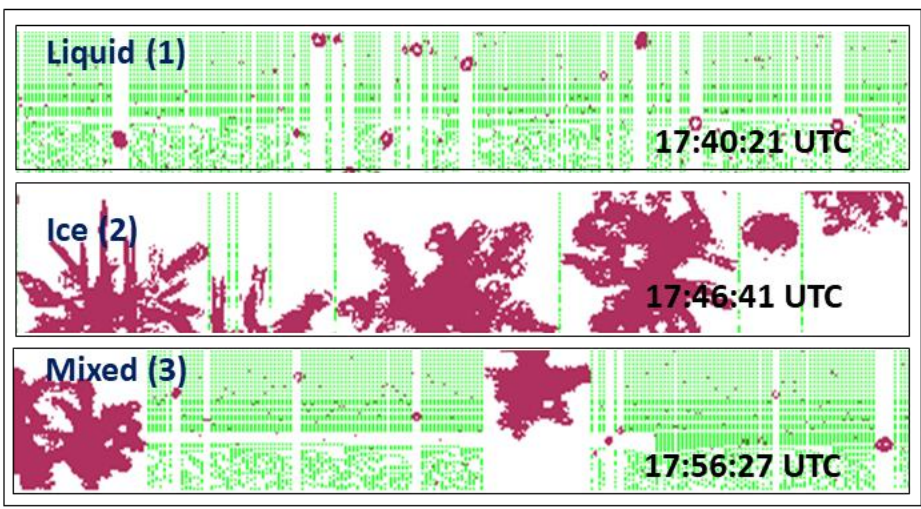

1044 Figure 3. Similar to Figure 2, but for a time series in RF03. The MODIS satellite image is on

1045 January 21, 2016, UTC 19:15:00. The three examples (1), (2), and (3) of Fast-2DC imageries are

1046 similar to those reported as Type 2, 1a and 1b in Costa et al. (2017), respectively. 


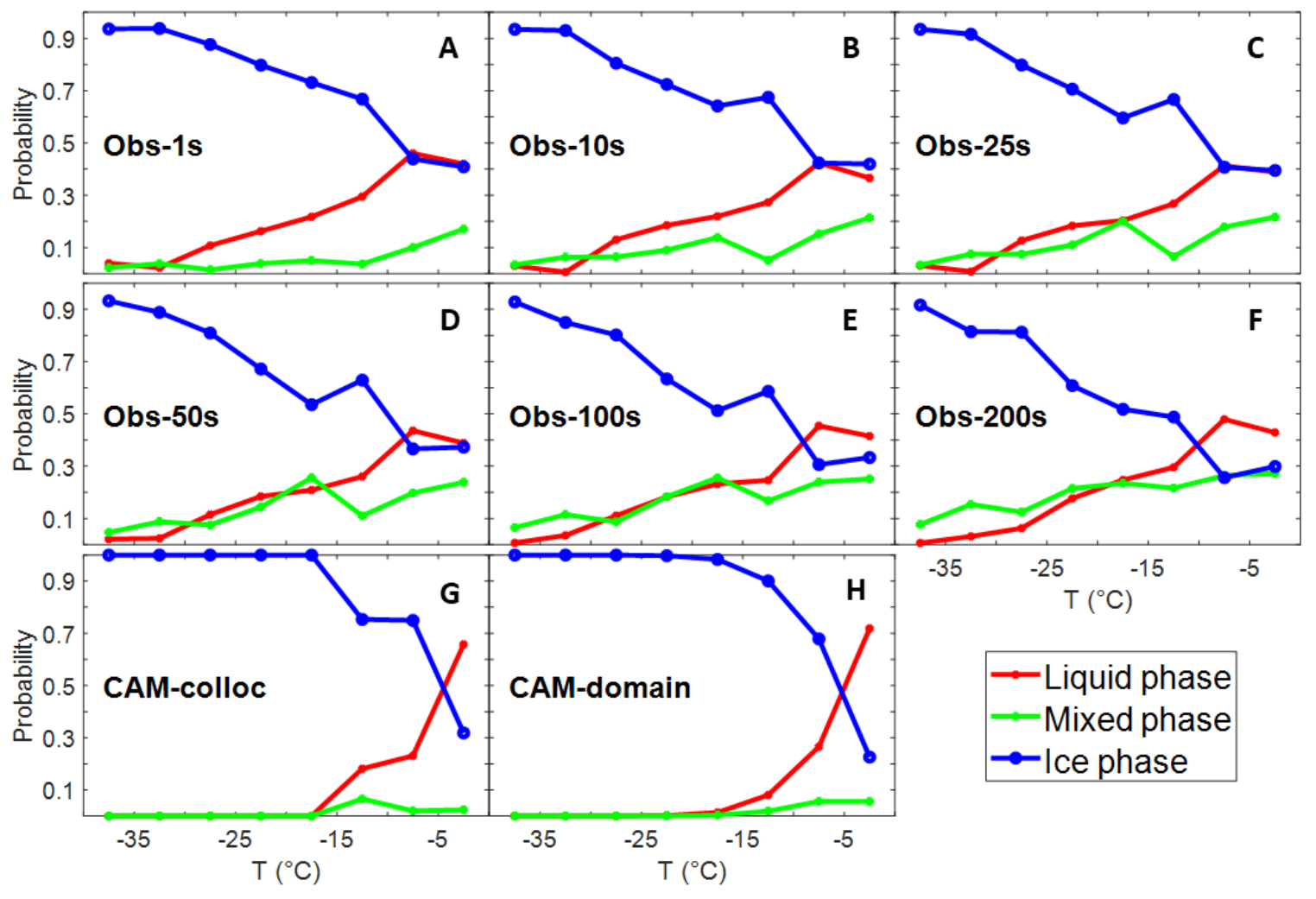

1048 Figure 4. Cloud phase occurrence frequency for all in-cloud conditions. Temperature is binned by 1049 every $5^{\circ} \mathrm{C}$. Sensitivity tests to various in-cloud thresholds are shown in Supplementary Figures S3 $1050-\mathrm{S} 5$. 

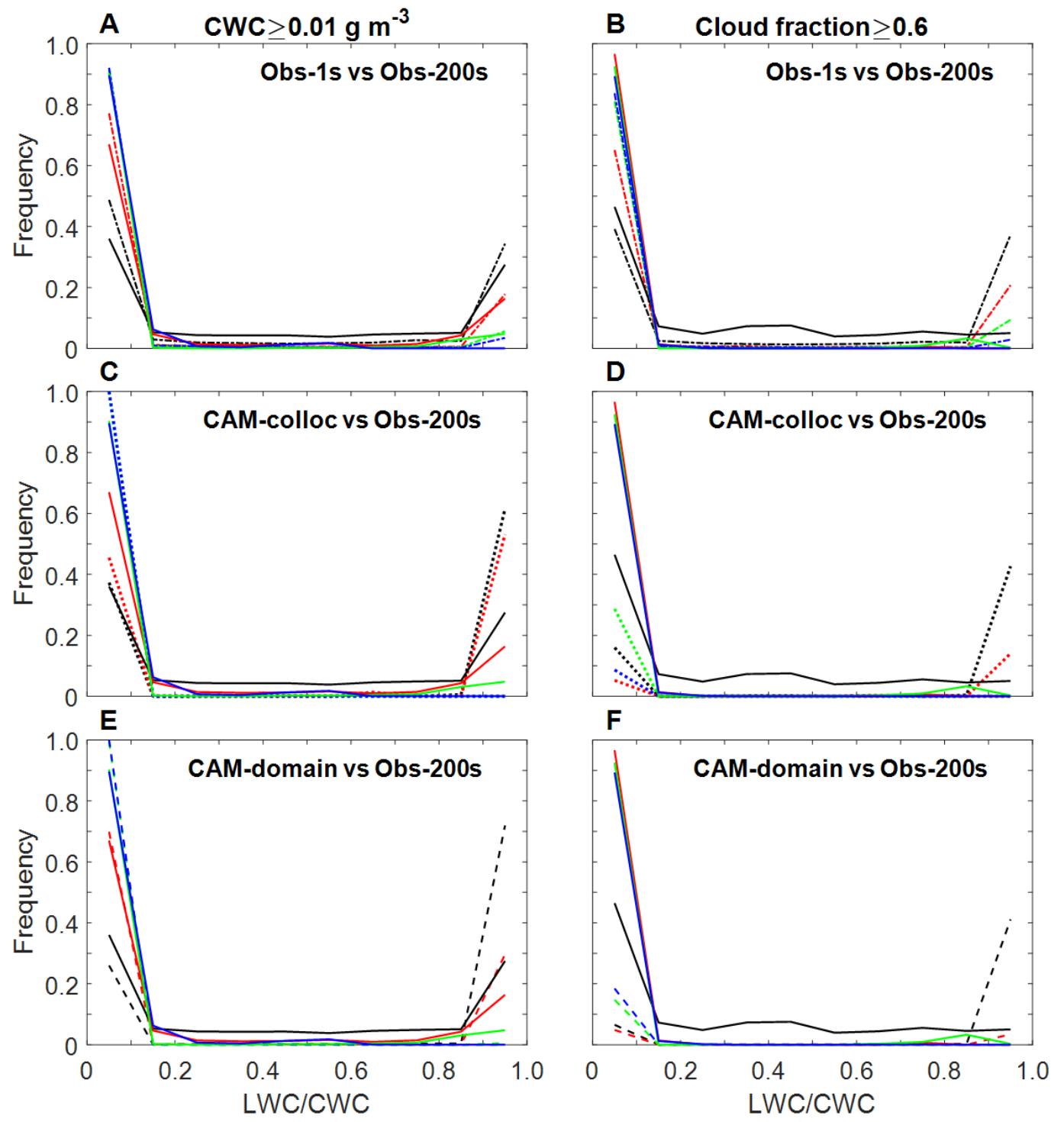

\begin{tabular}{|c|c|c|c|c|}
\hline $\begin{array}{r}\text { Obs-1s: } \\
\text { Obs-200s: } \\
\text { CAM-colloc: } \\
\text { AM-domain: }\end{array}$ & $\begin{aligned}-10^{\circ} & \leq \mathrm{T}<0^{\circ} \mathrm{C} \\
-10^{\circ} & \leq \mathrm{T}<0^{\circ} \mathrm{C} \\
-10^{\circ} & \leq \mathrm{T}<0^{\circ} \mathrm{C} \\
-10^{\circ} & \leq \mathrm{T}<0^{\circ} \mathrm{C}\end{aligned}$ & $\begin{aligned}-20^{\circ} & \leq \mathrm{T}<-10^{\circ} \mathrm{C} \\
-20^{\circ} & \leq \mathrm{T}<-10^{\circ} \mathrm{C} \\
-20^{\circ} & \leq \mathrm{T}<-10^{\circ} \mathrm{C} \\
--20^{\circ} & \leq \mathrm{T}<-10^{\circ} \mathrm{C}\end{aligned}$ & $\begin{aligned}-30^{\circ} & \leq \mathrm{T}<-20^{\circ} \mathrm{C} \\
-30^{\circ} & \leq \mathrm{T}<-20^{\circ} \mathrm{C} \\
-30^{\circ} & \leq \mathrm{T}<-20^{\circ} \mathrm{C} \\
- & -30^{\circ} \leq \mathrm{T}<-20^{\circ} \mathrm{C}\end{aligned}$ & $\begin{aligned}-40^{\circ} & \leq \mathrm{T}<-30^{\circ} \mathrm{C} \\
- & -40^{\circ} \leq \mathrm{T}<-30^{\circ} \mathrm{C} \\
- & -40^{\circ} \leq \mathrm{T}<-30^{\circ} \mathrm{C} \\
--- & -40^{\circ} \leq \mathrm{T}<-30^{\circ} \mathrm{C}\end{aligned}$ \\
\hline
\end{tabular}

1052 Figure 5: Occurrence frequencies of LWC/CWC ratios compared between Obs-200s (solid line in 1053 all sub-panels) and other data, i.e., Obs-1s (a, b), CAM-collocated (c, d) and CAM-domain (e, f). 1054 Two in-cloud thresholds are used: $\mathrm{CWC} \geq 0.01 \mathrm{~g} \mathrm{~m}^{-3}$ (left) and cloud fraction $\geq 0.6$ (right). Obs- $1 \mathrm{~s}$ 1055 data calculate cloud fraction in $10 \mathrm{~s}$ intervals $( \pm 5 \mathrm{~s})$. The number of samples of liquid, mixed and 1056 ice phases are shown in Table 1. Figure S6 and Table $\mathrm{S} 4$ show results using $5^{\circ} \mathrm{C}$ bins. 

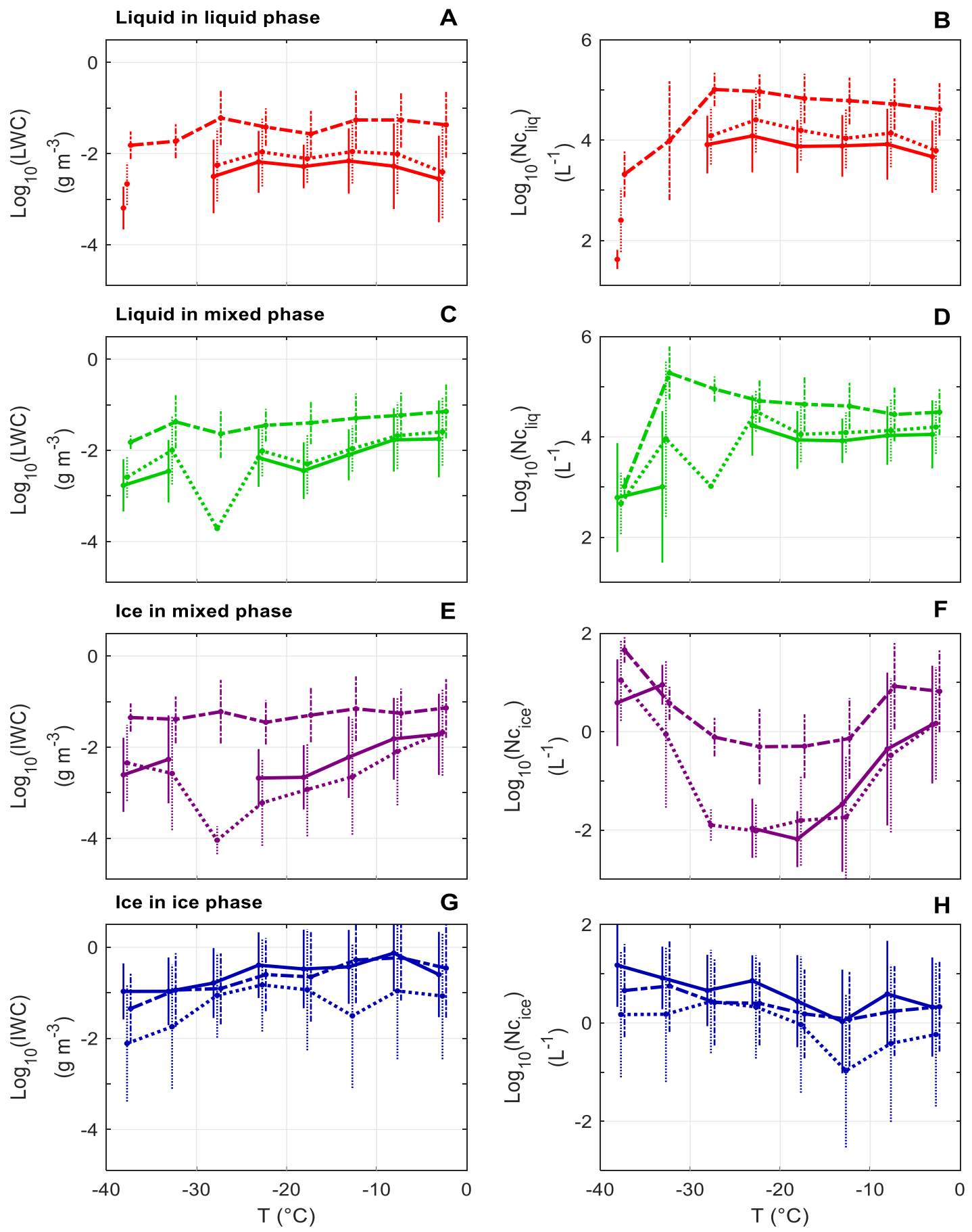

\begin{tabular}{|c|c|c|c|c|}
\hline Obs-1s: & ------. liquid phase & ------. Liquid in mixed phase & -----. Ice in mixed phase & --ー-ー-. ice phase \\
\hline Obs-100s: & $\ldots \ldots \ldots \ldots$ liquid phase & $\ldots \ldots \ldots . . . .$. Liquid in mixed phase & ............. Ice in mixed phase & ............. ice phase \\
\hline Obs-200s: & — liquid phase & Liquid in mixed phase & — Ice in mixed phase & — ice phase \\
\hline
\end{tabular}

1058 Figure 6: Geometric means of $\mathrm{LWC}$, IWC, $\mathrm{Nc}_{\text {liq }}$ and $\mathrm{Nc}_{\text {ice }}$ for three cloud phases at $5^{\circ} \mathrm{C}$ intervals 1059 between $-40^{\circ}-0^{\circ} \mathrm{C}$ for various scales of observations. Whiskers in Figures $6-8$ represent \pm one 
1060 standard deviation, and their number of samples are shown in supplementary Figures S7-S9.

1061 Besides the restriction of no more than $10 \%$ of the averaged segments reporting missing values,

1062 the analysis is restricted to observation data with at least one second of CWC $>0.001 \mathrm{~g} \mathrm{~m}^{-3}$ and at 1063 least one second of either $\mathrm{Nc}_{\text {liq }}>100 \mathrm{~L}^{-1}$ or $\mathrm{Nc}_{\text {ice }}>0.01 \mathrm{~L}^{-1}$. 

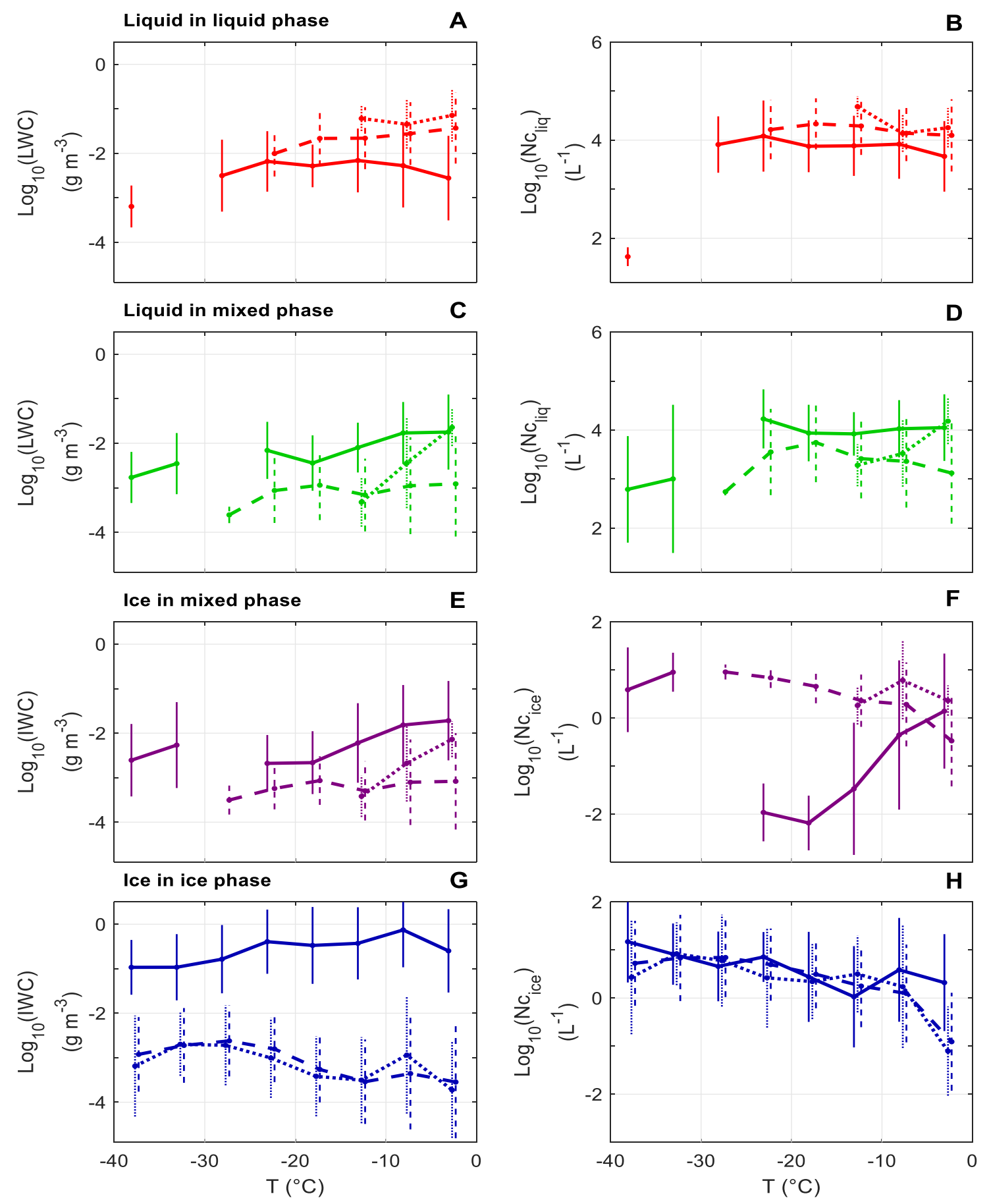

\begin{tabular}{|c|c|c|c|c|}
\hline $\begin{array}{l}\text { Obs-200s: } \\
\text { CAM-colloc: } \\
\text { CAM-domain: }\end{array}$ & 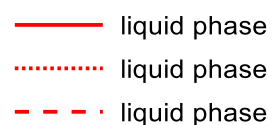 & $\begin{array}{l}\text { Liquid in mixed phase } \\
\ldots . . . . . . . . \\
\ldots \ldots\end{array}$ & 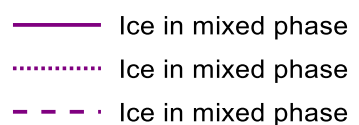 & 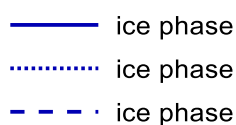 \\
\hline
\end{tabular}

Figure 7: Similar to Figure 6, but for Obs-200s, CAM-collocated and CAM-domain datasets. In addition to the restriction of Obs-200s data as mentioned in Figure 6 caption, simulation output 
1067 are restricted to those with both "CLDICE" and "CLDLIQ" $\geq 4.68 \mathrm{e}-5 \mathrm{~g} \mathrm{~m}^{-3}$. These restrictions 1068 help to filter out very low values of IWC, LWC, $\mathrm{Nc}_{\text {liq }}$ and $\mathrm{Nc}_{\text {ice. }}$ Particularly, restrictions on 1069 simulated CLDICE and CLDLIQ are used since filtering out low IWC and LWC alone does not 1070 exclude all of the low number concentrations reported in NUMICE and NUMLIQ. 

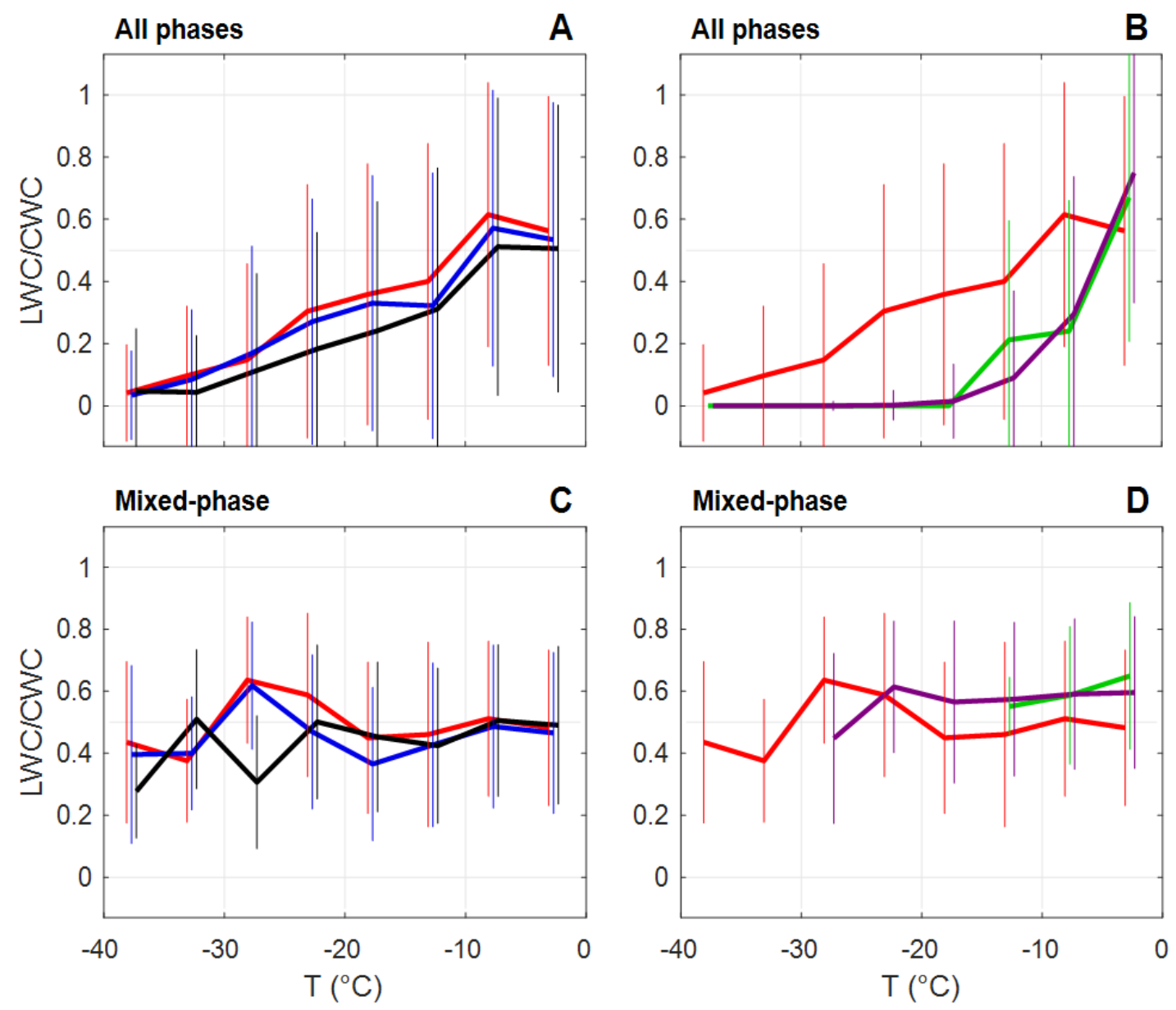

Obs-1s:

Obs-100s:

Obs-200s:

CAM-colloc:

CAM-domain:

1072 Figure 8: Average LWC/CWC for (a, b) total in-cloud conditions and (c, d) mixed phase only.

1073 (Left column) Obs-1s, Obs-100s and Obs-200s. (Right column) Obs-200s, CAM-collocated and 1074 CAM-domain. 


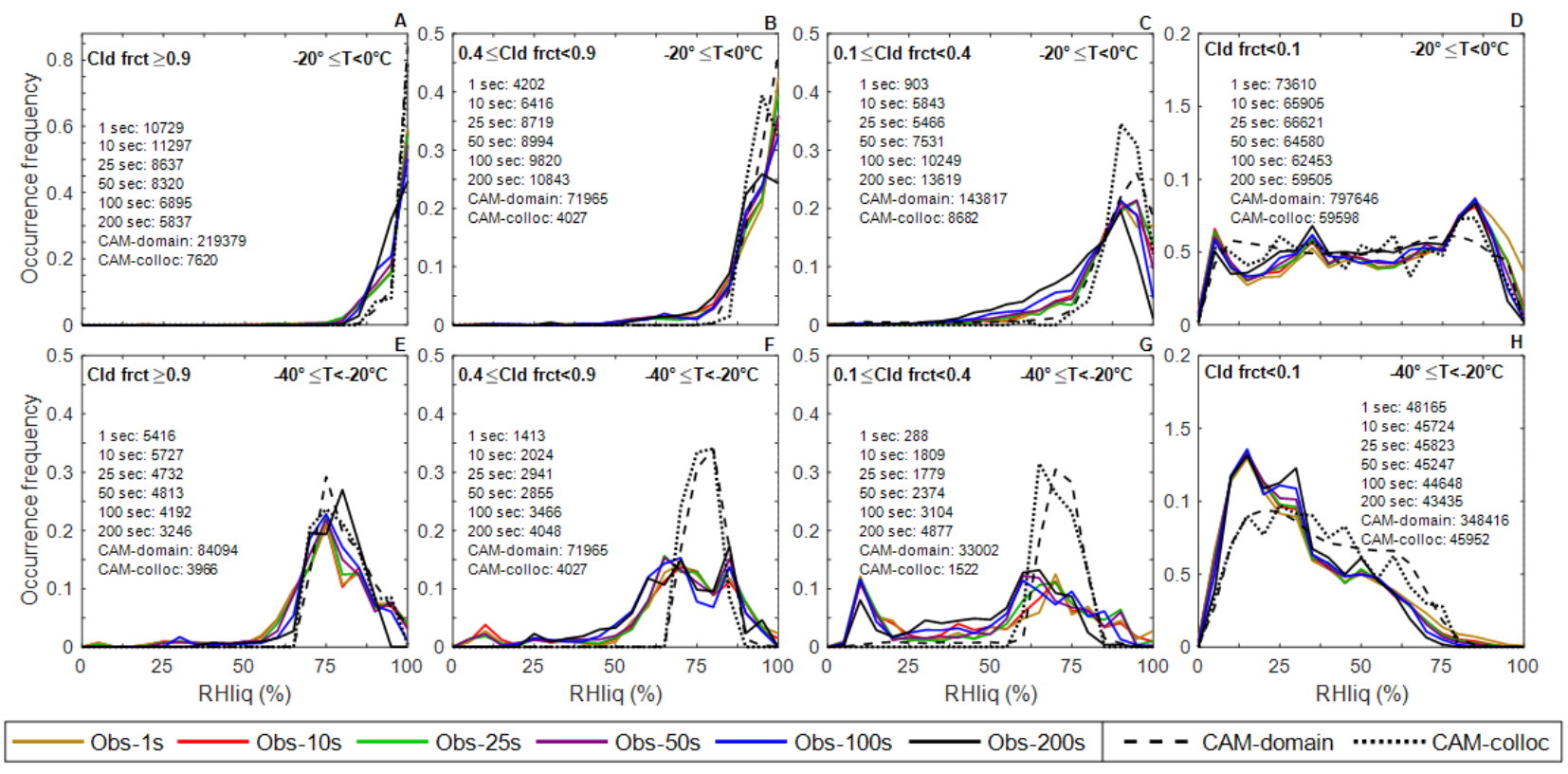

1076 Figure 9: RHliq PDFs for various temperatures and cloud fractions. $(\mathrm{a}-\mathrm{d})-20^{\circ}-0^{\circ} \mathrm{C}$; (e-h) $-40^{\circ}-$ $1077-20^{\circ} \mathrm{C}$. Various scales of observations (colored solid lines), CAM-collocated (dotted) and CAM1078 domain (dashed) data are shown. Results are binned by $5 \%$ of RHliq, except for $<2.5 \%$. The 1079 number of samples generally increases with increasing averaging scales when using less strict 1080 cloud fraction restrictions (i.e., cloud fraction $<0.9$ ), since it is more likely for samples at larger 1081 scales to be partially in-cloud than samples at smaller scales. 

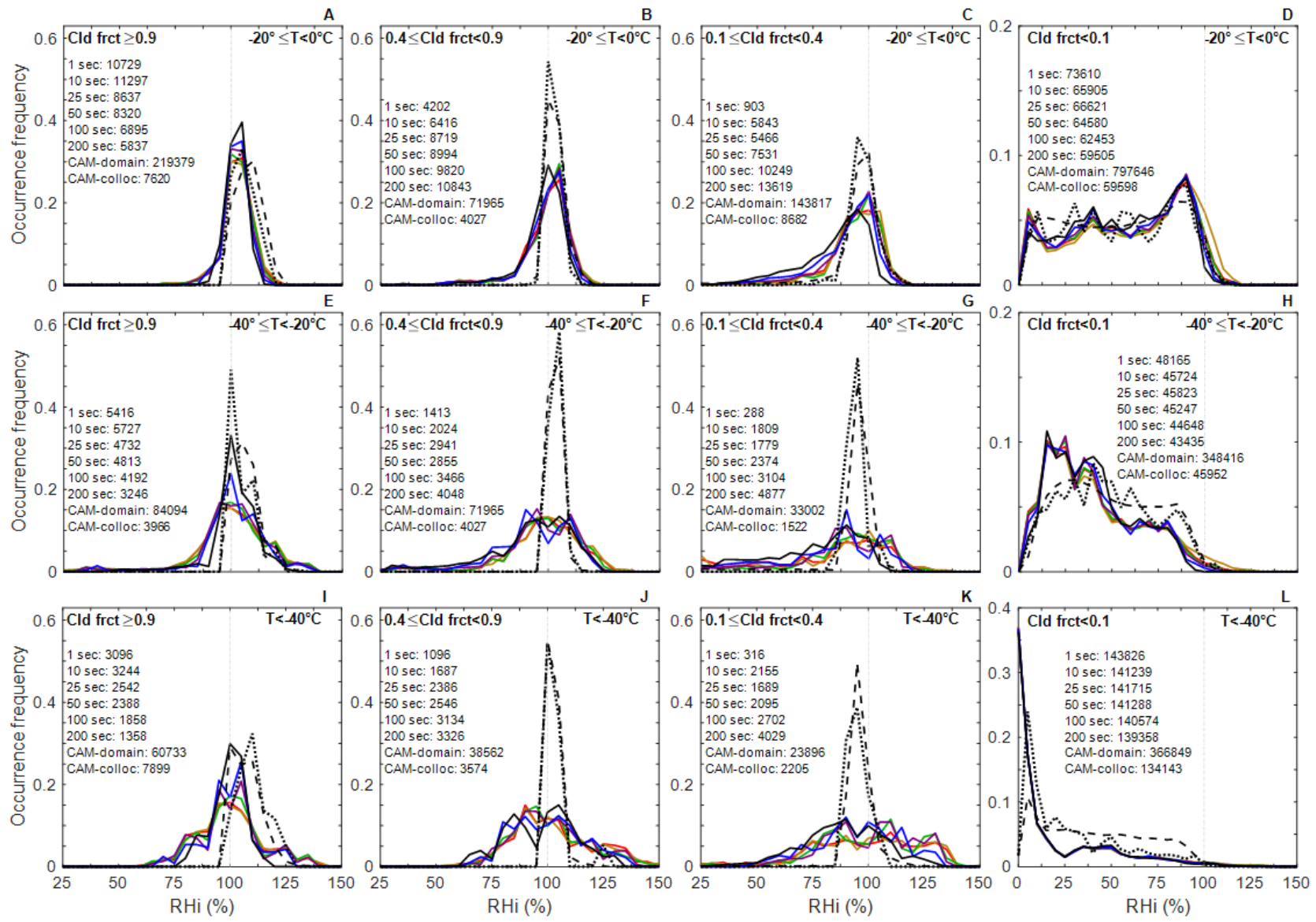

1082

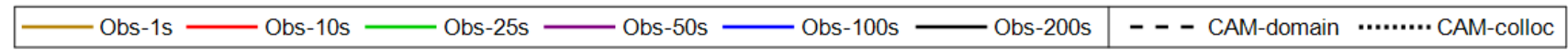

1083 Figure 10: Similar to Figure 9, except for RHi. 

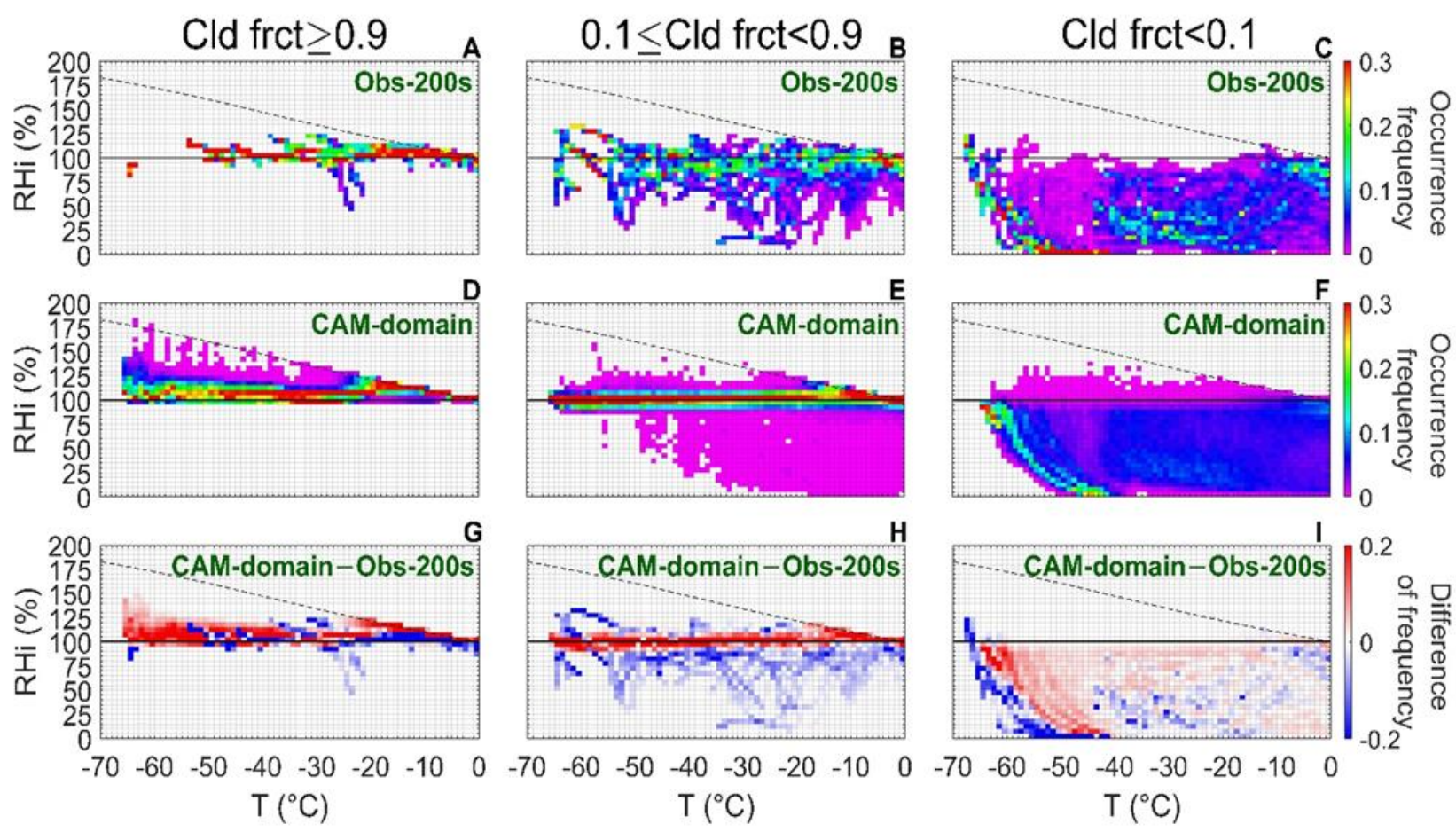

Figure 11: RHi frequency distributions at various temperatures for $(a-c)$ Obs-200s, (d-f) CAM-

1086 domain and (g-i) their differences (CAM-domain - Obs-200s). Frequency in each $1{ }^{\circ} \mathrm{C} \times 5 \%$ bin is 1087 normalized by the total number of samples in each $1{ }^{\circ} \mathrm{C}$ interval. Solid and dashed lines show ice 1088 and liquid saturation, respectively. 

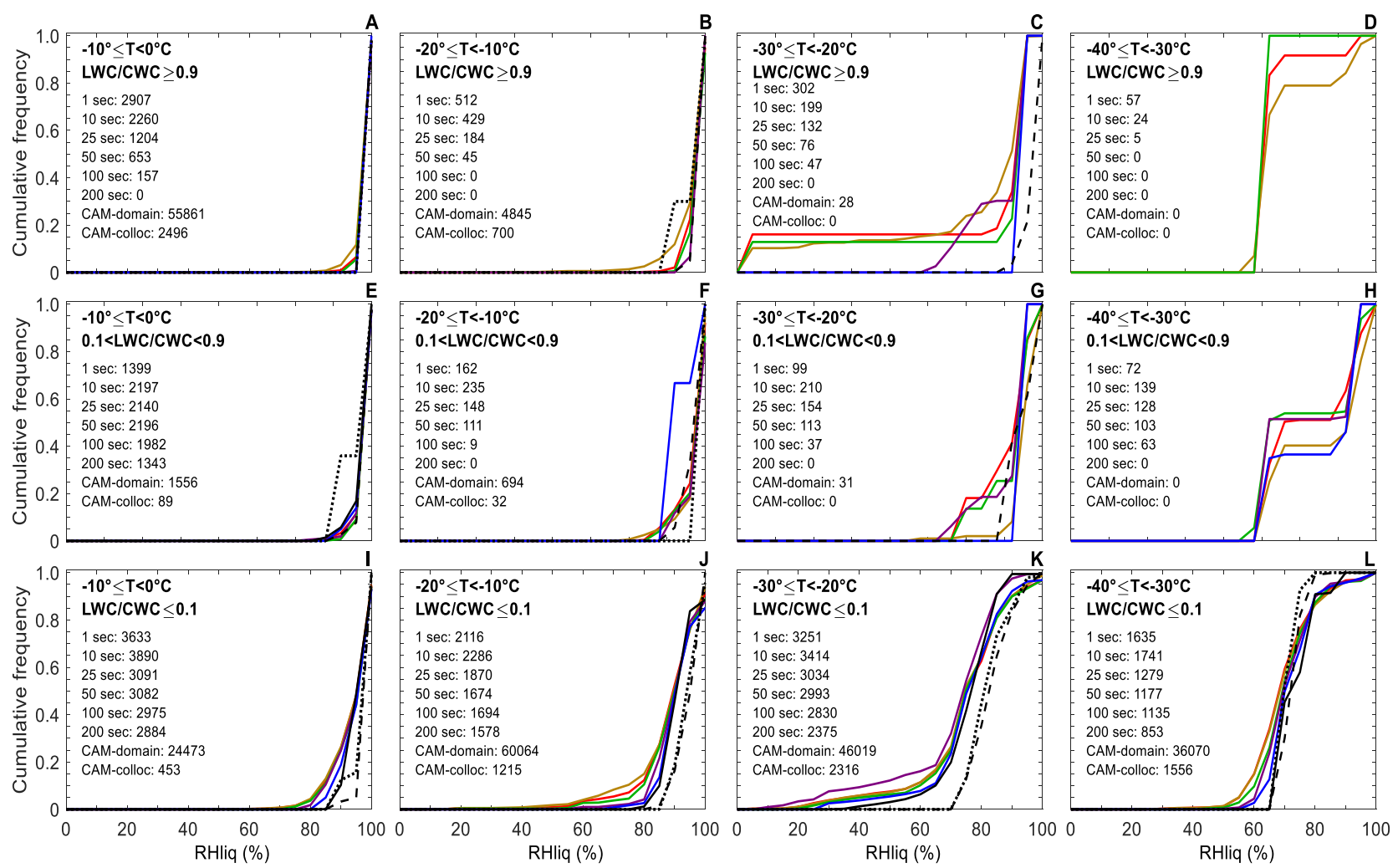

\begin{tabular}{|c|}
\hline Obs-1s $=$ Obs-10s Obs-25s Obs-50s - Obs-100s - Obs-200s \\
\hline
\end{tabular}

1090 Figure 12: RHliq CFDs for three cloud phases, restricted to cloud fraction $\geq 0.9$. Results are

1091 binned by $5 \%$ of RHliq, except for $<2.5 \%$. 

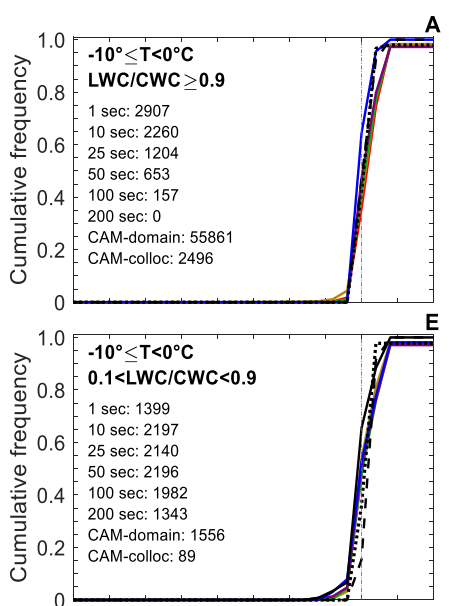

$1.0=-10^{\circ} \leq \mathrm{T}<0^{\circ} \mathrm{C}, \quad, \quad$,

$\begin{array}{lll}\text { Uे } & -10^{\circ} \leq \mathrm{T}<0^{\circ} \mathrm{C} \\ & \mathrm{LWC} / \mathrm{CWC} \leq 0.1\end{array}$

¿ 0.8 : $1 \mathrm{sec}: 3633$

®는 $0.6=-10 \mathrm{sec}: 3890$

$25 \mathrm{sec}: 3091$
$50 \mathrm{sec}: 3082$

$\sum_{\mathbb{W}}^{\infty} 0.4=100 \mathrm{sec}: 2975$

E 0.2 CAM-domain: 24473

CAM-colloc: 453
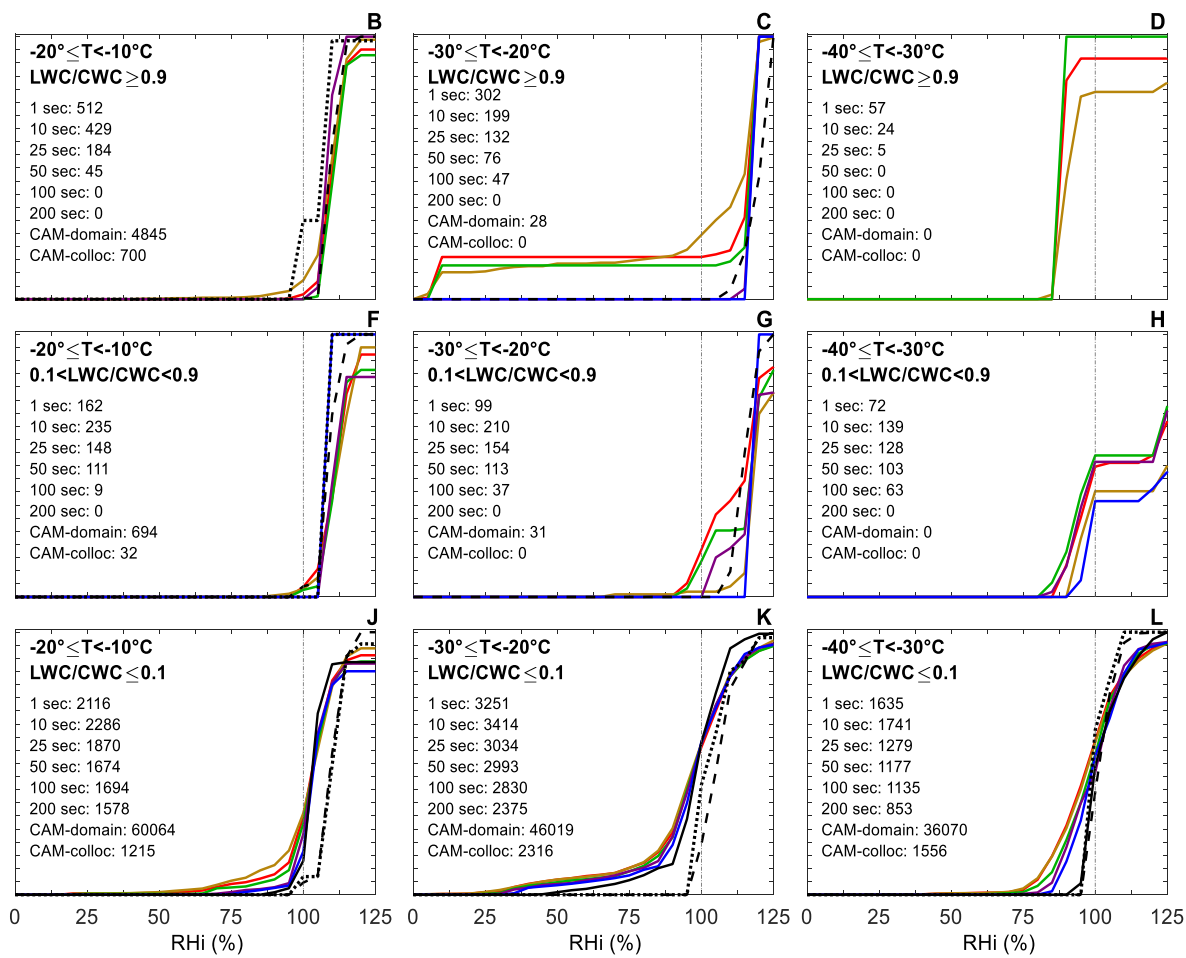

1092

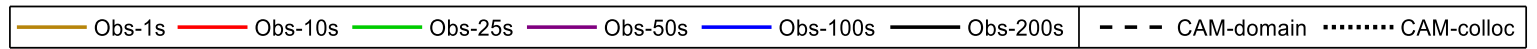

1093 Figure 13: Similar to Figure 12, except for RHi. 
ISS \& Cld frct $<0.1$
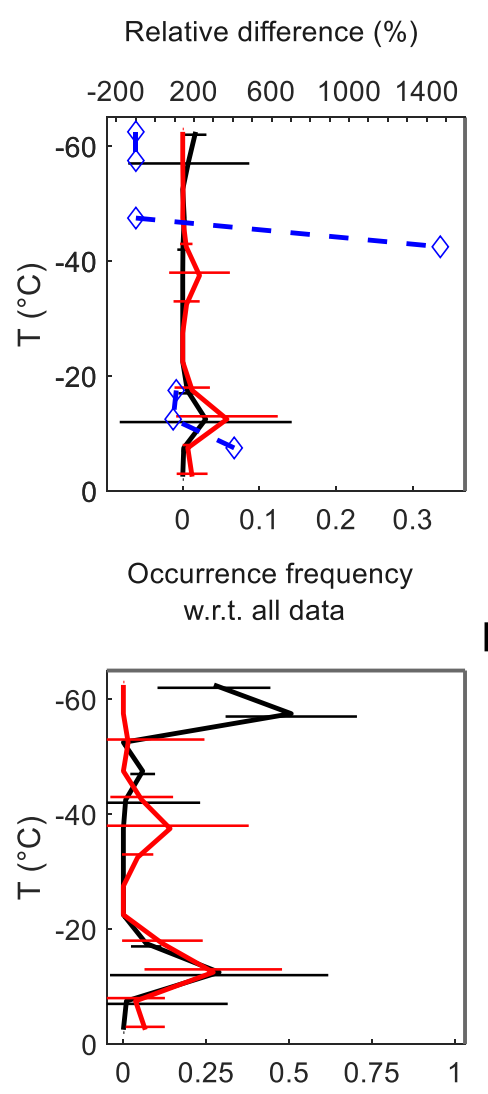

Occurrence frequency w.r.t. three conditions

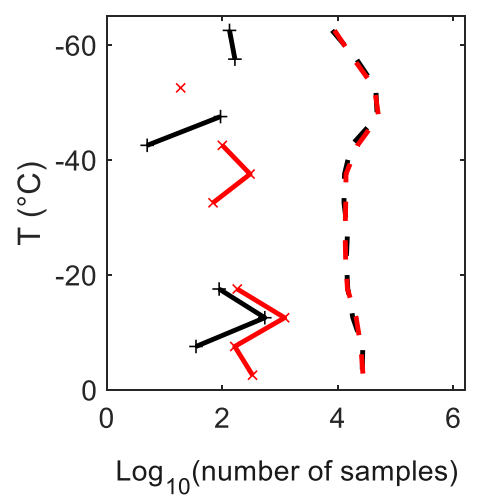

ISS \& Cld frct $\geq 0.6$

Relative difference (\%)

A $\quad-200 \quad 200 \quad 600 \quad 10001400$

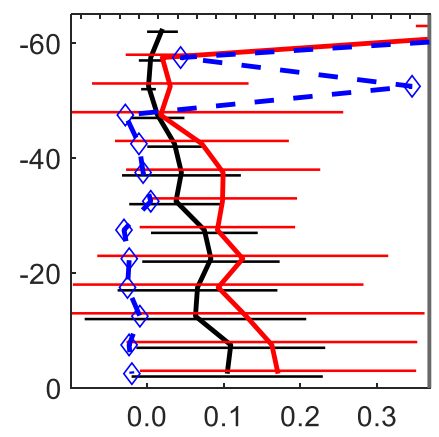

Occurrence frequency w.r.t. all data

D

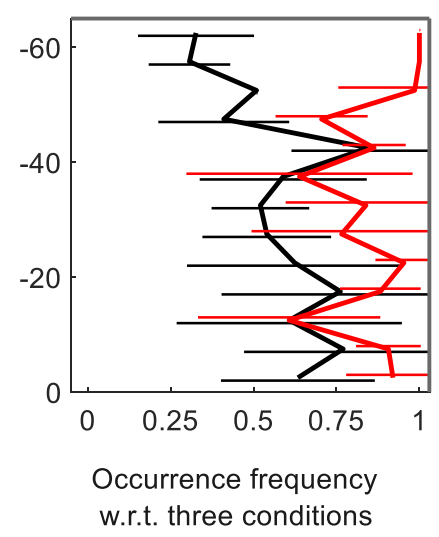

G

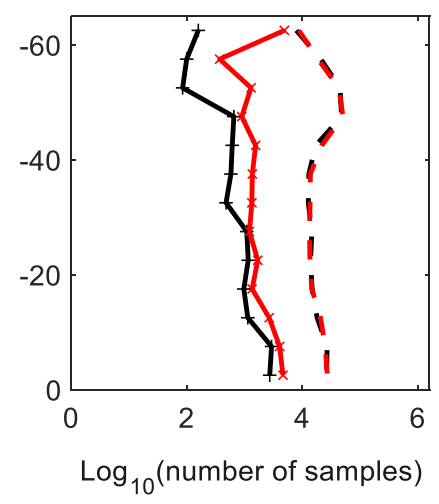

non-ISS \& Cld fret $\geq 0.6$

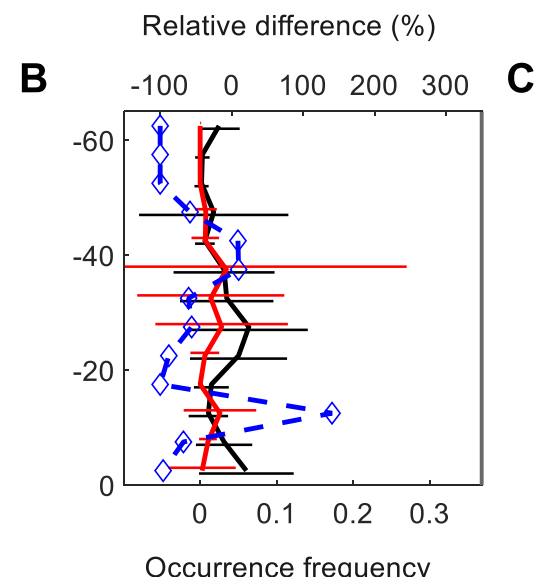

E w.r.t. all data

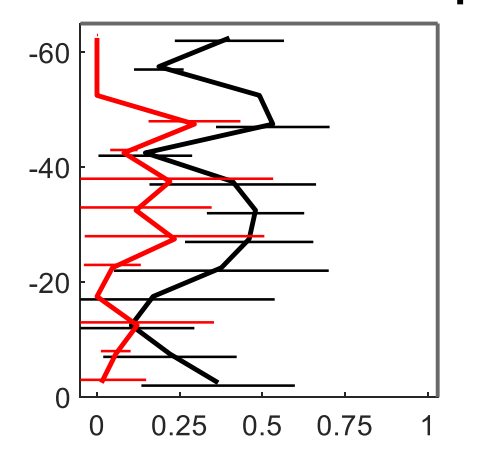

Occurrence frequency w.r.t. three conditions

H

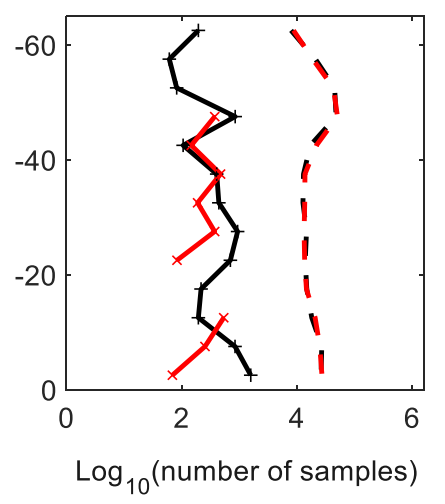

$\diamond-\cdots$

(CAM-colloc-Obs-200s)/Obs-200s $\times 100 \%$

1095 Figure 14: Vertical profiles for the occurrence frequencies of three cases: (first column) ISS at 1096 cloud fraction $<0.1$, (second column) ISS at cloud fraction $\geq 0.6$, and (third column) non-ISS at 1097 cloud fraction $\geq 0.6$ for Obs-200s and CAM-collocated data. (a-c) Frequency normalized by the 
1098 total number of samples at each $5^{\circ} \mathrm{C}$ intervals. Blue dashed lines show the relative differences (in $1099 \%$, upper abscissa): (CAM-collocated - Obs-200s)/Obs-200s $\times 100 \%$. Horizontal whiskers 1100 represent the corrected sample standard deviation for 18 research flights. (d-e) Frequency 1101 normalized by the number of samples of these three conditions. (e-f) Number of samples for each 1102 specific condition in that column (solid lines with markers), and number of all the samples at each $1103 \quad 5^{\circ} \mathrm{C}$ interval (dashed lines). 